Portland State University

PDXScholar

6-1-1992

\title{
A Descriptive Study of the Implementation of an Integrated Whole Language Approach at the Fifth Grade Level
}

Ardyth Shapiro

Portland State University

Follow this and additional works at: https://pdxscholar.library.pdx.edu/open_access_etds

Part of the Educational Administration and Supervision Commons, and the Educational Leadership Commons

Let us know how access to this document benefits you.

\section{Recommended Citation}

Shapiro, Ardyth, "A Descriptive Study of the Implementation of an Integrated Whole Language Approach at the Fifth Grade Level" (1992). Dissertations and Theses. Paper 1205.

https://doi.org/10.15760/etd.1204

This Dissertation is brought to you for free and open access. It has been accepted for inclusion in Dissertations and Theses by an authorized administrator of PDXScholar. Please contact us if we can make this document more accessible: pdxscholar@pdx.edu. 


\title{
A DESCRIPTIVE STUDY OF THE IMPLEMENTATION OF AN INTEGRATED WHOLE LANGUAGE APPROACH AT
}

THE FIFTH GRADE LEVEI

by

ARDYTH SHAPIRO

A dissertation submitted in partial fulfillment of the requirements for the degree of

\author{
DOCTOR OF EDUCATION \\ in \\ EDUCATIONAL LEADERSHIP: \\ ADMINISTRATION AND SUPERVISION
}

Portland State University

01992 


\section{TO THE OFFICE OF GRADUATE STUDIES:}

The members of the Committee approve the dissertation of Ardyth Shapiro presented June 1, 1992.

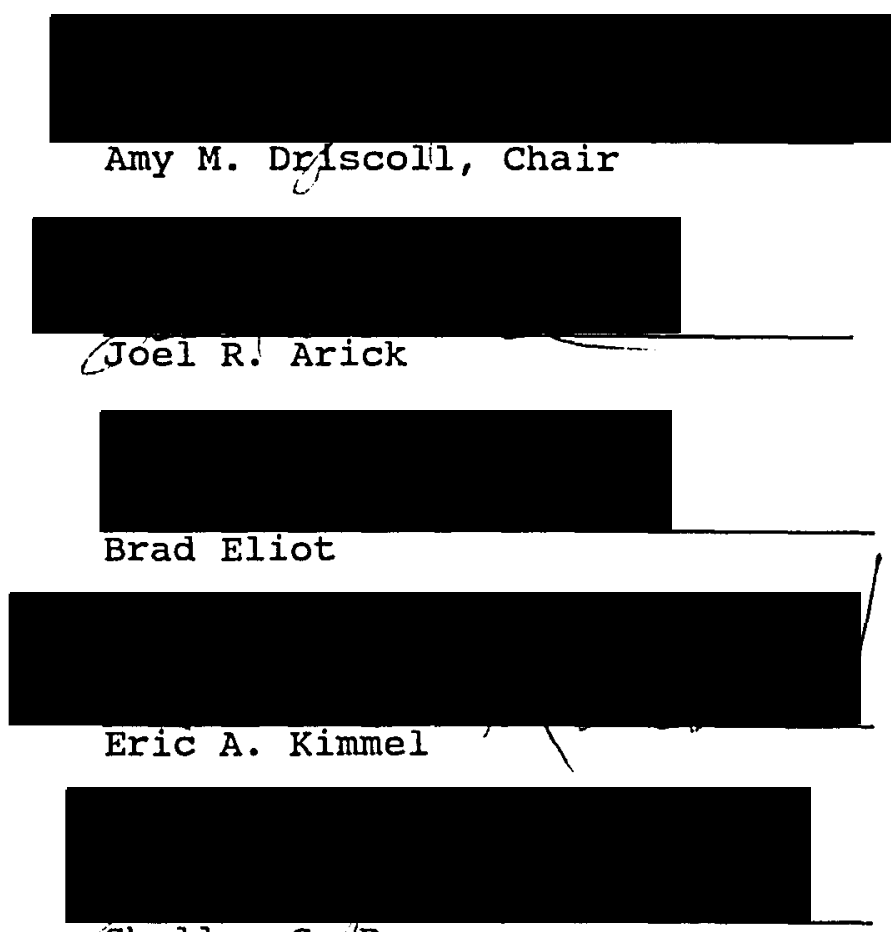

$$
\text { Shelley C.//Reece }
$$

APPROVED :

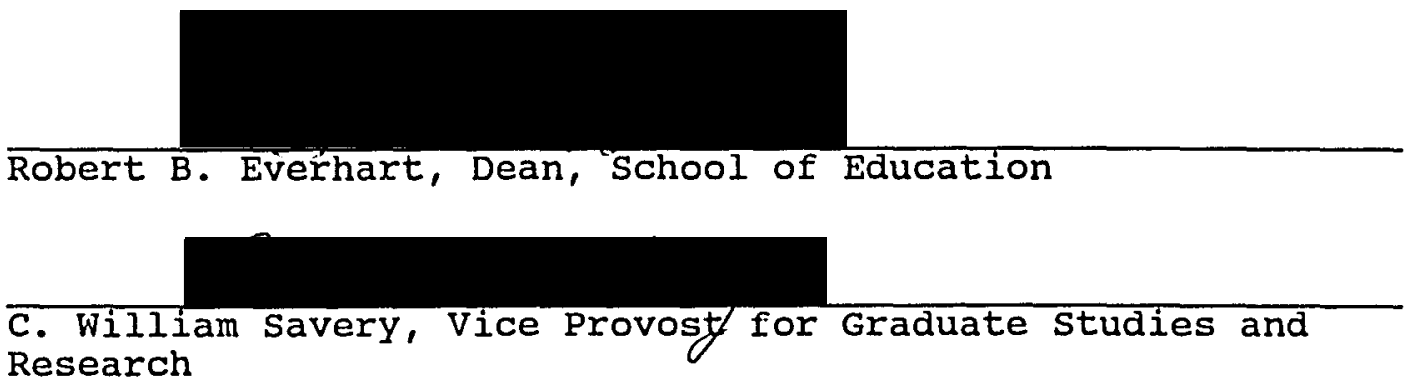


AN ABSTRACT OF THE DISSERTATION OF Ardyth Shapiro for the Doctor of Education in Educational Leadership:

Administration and Supervision presented June 1, 1992.

Title: A Descriptive Study of the Implementation of an Integrated whole Language Approach at the Fifth Grade Level.

APPROVED BY THE MEMBERS OF THE DISSERTATION COMMITTEE:

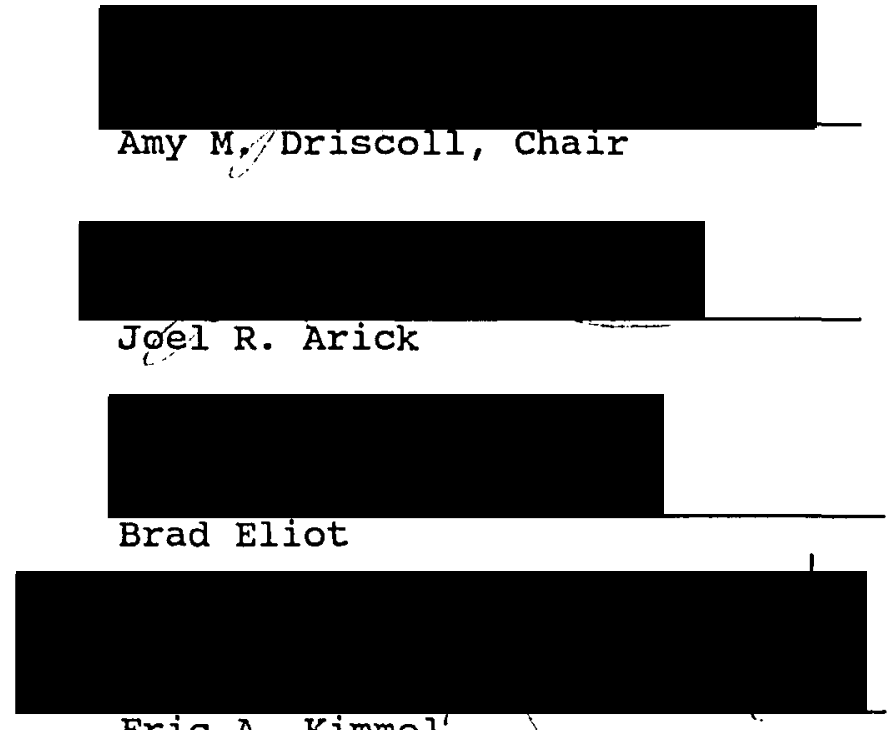

Eric A. Kimmel'

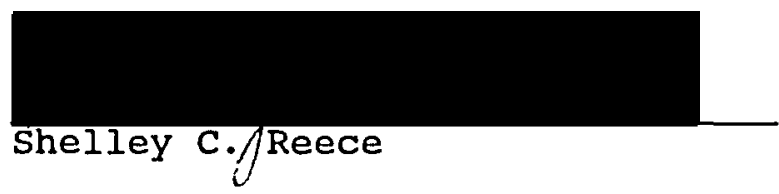

The purpose of this study was to describe the implementation of a major curriculum change at the fifth grade level in two different school district settings; an 
urban district and a suburban district. The major curriculum change was a shift from traditional reading and language arts instructional approaches to an Integrated Whole Language instructional approach. The implementation of this change was examined on the basis of self-reports by administrators, teachers, and students and was analyzed in the context of organizational factors in schools that have typically influenced change. These included school district demographics, the decision making process, administrative support, inservice training, the principal's leadership role, and resources available. Additionally, the study investigated the relationship between teacher self-reported implementation behaviors and student self-reported attitudes and behaviors related to reading and writing.

A blend of qualitative and quantitative research methodologies was employed to describe the implementation as a change process. Extensive descriptive data was collected from school districts, individual schools, administrators and teachers. Teacher administrator interviews were conducted to develop description of organizational factors, and teachers reported their implementation behaviors on a questionnaire. Teacher implementation scores were used to describe difference between teachers, schools, and districts.

A major conclusion was that change is an individual and developmental process. Differences existed in teacher 
implementation scores and perceptions of the change. It was also concluded that significant differences between administrator and teacher interview responses were related to different knowledge and involvement levels, and a reported lack of principal support. Within school differences and between district differences were found and were related to contextual factors. 


\section{ACKNOWLEDGEMENTS}

This dissertation is dedicated first to my husband, Herbert J. Shapiro. His love and support are a part of every page.

The quality of my research and its presentation to the education profession, I owe to Dr. Amy Driscoll for her encouragement, friendship, and model of excellence over the years of our professional relationship.

I also owe my thanks to the support of my daughter Annie Bell, my brother Dr. David Rosencrantz, my mother Rose Rosencrantz, and my friend Tamra Ray. Additional appreciation must be extended to Dr. Brad Eliot, Dr. Eric Kimmel, Dr. Joel Arick, Dr. Shelley Reece, Dr. John Lind, and Dr. Kathy Westbrook for helping me along the way.

Finally, I must give credit to my research assistant Kelly Driscoll for her assistance and friendship with this project. I will always be grateful to my team for all their support. 
TABLE OF CONTENTS

PAGE

ACKNOWLEDGEMENTS. • . . . . . . . . . . . . . . . . iii

LIST OF TABLES. . . . . . . . . . . . . . . . . $\mathrm{x}$

LIST OF FIGURES . . . . . . . . . . . . . . . . . $x i$

CHAPTER

I STATEMENT OF THE PROBLEM . . . . . . . . . 1

Introduction . . . . . . . . . . . 2

statement of the Problem . . . . . . 2

Background of the Study. . . . . . . . 4

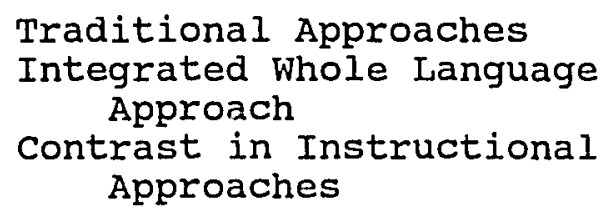


Summary. . . . . . . . . . . 23

Dissertation Format. . . . . . . . 23 REVIEW OF THE LITERATURE . . . . . . . . . 24

Introduction . . . . . . . . . . 24

Study Purpose

Chapter Contents

Approaches to Reading and Language

Arts Instruction......... . 27

Traditional Approaches to Instruction

Integrated whole Language Approach to Instruction

Contrasts Between Approaches

Rationale for studying Integrated whole Language Approach

Implementation as Change . . . . . . 34

Approaches to studying Implementation. . 37

Measuring Implementation

Measuring Implementation Through Determinants

Measuring Implementation Through Achievement

Measuring Implementation Through "Reported Use" Methodology

Studies of Change. . . . . . . . . 44

Contextual Factors Affecting Change

Mechanisms Within Schools Affecting Change

External Factors Affecting Change

The Role of Administrator in the Change Process

Teachers and Change. . . . . . . . 56

Teacher Characteristics

Teacher Beliefs 
Teacher Implementation

Behavior

Teacher Behaviors and Student Behaviors. . . . . . . . . . 65

Teacher Behaviors and student

Attitudes. . . . . . . . . . 68

Summary. . . . . . . . . . . 70

III

STUDY METHODOLOGY. . . . . . . . . . 73

Introduction . . . . . . . . . . 73

Study Purpose

Chapter contents

Research Approach

Support for Proposed Approach

Research Questions

Sample . . . . . . . . . . . 80

Data Collection Procedures . . . . . 81

Pilot Study

Contextual Data collection

Interviews

Demographics

Teacher Questionnaires

student Questionnaires

Data Analysis Procedures . . . . . . 83

Summary. • . • . . . . . . . 87

Study Purpose

Chapter Contents and Format

Findings for Question one. . . . . . 89

Research Question and Analysis Procedures

Common Descriptions of the Change

Differences in Descriptions

Between Teachers and

Administrators 
Differences Within the Teacher Sample

Differences Within the Administration Sample

Differences Between Districts

Differences Within Individual Schools

Findings for Question Two. . . . . 101

Research Question and Analysis Procedures

Common Descriptions of Language Arts Instruction

Differences Between Districts

Differences Within Individual Schools

Findings for Question Three. . . . . 104

Research Question and Analysis Procedures

Differences Between Teachers

Differences Between Schools

Common Descriptions of

Language Arts Instruction

Differences Between Districts

Summary

Findings for Question Four . . . . . 112

Research Question and

Analysis Procedures

Relationship Between

Implementation score

and Education

Relationship Between

Implementation Score

and Years of Teaching

Experience

Relationship Between

Implementation score

and Teacher Age

Relationship Between

Implementation Score

and Teacher Gender

Summary

Findings for Question Five . . . . . 116

Research Question and

inalysis Procedures 


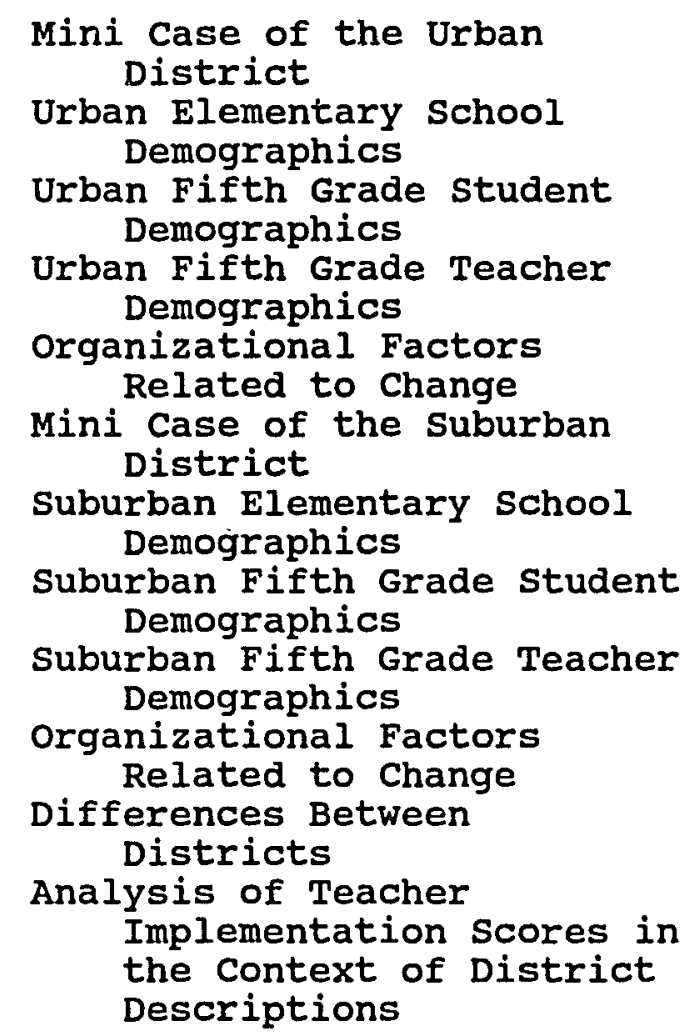

Findings for Question Six. . . . . . 126

Research Question and Analysis Procedures

Student Honesty in Responding

Student Descriptions of Attitudes and

Behaviors Toward Language Arts . . 127

Reading Activities

Writing Activities

Free Time in School and at Home

Books Read and Time Spent Reading outside of School

Differences Between Districts

Findings for Question Seven. . . . . 128

Research Question and

Summary

Analysis Procedures 
CONCLUSIONS AND RECOMMENDATIONS. . . . . 136

Introduction . . . . . . . . . 136

Study Purpose

Chapter contents and Format

Conclusions. • . . . . . . . . 137

Question 1

Question 2

Question 3

Question 4

Question 5

Question 6

Question 7

Recommendations. . . . . . . . . 146

Administrators

Teachers

Program Developers

Future Research

Summary. • . . . . . . . . . . 150

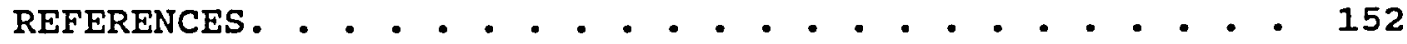

APPENDICES

A ADMINISTRATOR AND TEACHER INTERVIEW

QUESTIONS. . . . . . . . . . . . . . 162

B TEACHER QUESTIONNAIRE. . . . . . . . . . 165

C STUDENT QUESTIONNAIRE. . . . . . . . . . . 171

D SCATTERGRAMS . . . . . . . . . . . 175 


\section{LIST OF TABLES}

TABLE

PAGE

I Differences in Teacher Implementation Scores Reported in Percentages for Districts. . . . . . . . . . 109 


\section{LIST OF FIGURES}

FIGURE

PAGE

1. Frequency Distribution for Teacher Sample. . 106

2. Differences in Teacher Implementation Scores by Districts and Schools. . . . 108

3. Differences in Implementation Scores for Selected Schools... . . . . . 109

4. Education Levels and Implementation Scores . . . . . . . . . . . . 113

5. Teacher Experience and Implementation Scores . . . . . . . . . . . . 114

6. Age and Implementation Scores. . . . . . 115

7. Gender and Implementation Scores . . . . 115 


\section{CHAPTER I}

STATEMENT OF THE PROBLEM

This chapter provides an overview of a descriptive study of the implementation of an Integrated Whole Language instructional approach at the fifth grade level. The implementation is conceptualized as a change process and is examined in the context of school organizational factors which influence change. Implementation of an Integrated Whole Language instructional approach represents a significant shift from traditional instructional approaches in reaching and writing, so it represents a major curricular change for schools.

This chapter begins with a statement of the problem and a rationale for studying the implementation of an Integrated Whole Language instructional approach. Background for the study is provided through a literaturebased description of the contrast between traditional approaches to language arts instruction and the Integrated Whole Language approach, and a conceptualization of implementation as change. The literature summary provides a foundation for the framework of assumptions and research questions. Definition of the terms are provided for clarification of use in this study. The significance of 
this study is established by presentation of potential contributions to the knowledge base. Finally, summaries of the research methodology an limitations are presented. the final section outlines the contents of the remaining chapters.

\section{INTRODUCTION}

The purpose of this study is to describe the implementation of a major curriculum change (at the fifth grade level) in two different school district settings; an urban district and a suburban one. The major curriculum change examined is the shift from a traditional reading and language arts program to an Integrated whole Language program. The implementation of this change is examined on the Dasis of self-reports by teachers, students, and administrators and is described in the context of organizational factors in schools that have typically influenced change: school district demographics, decision making processes, administrative support, inservice training, the principal's leadership role, and resources available.

STATEMENT OF THE PROBLEM

The Integrated Whole Ianguage approach to language arts instruction is being adopted and implemented as a formal program of instruction in many urban and suburban 
school districts throughout the United states. These adoptions focus attention upon recent research findings describing how children learn to read and write. They also provide an impetus for both teachers and administrators to review their language arts programs from a new perspective, that of functional use as communication.

The Integrated Whole Language approach represents a change brought about by pressures from within the education profession (Anderson, Hiebert, Scott, \& Wilkinson, 1985) and by societal pressures (Rowan, 1990). As a curricular and instructional approach, it is probably the most widely published and extensively articulated innovation (Dillon \& O'Brien, 1992). The attention being given to the Integrated Whole Language approach directs this dissertation to study and describe its implementation as a highly significant change. When school districts initiate formal programs, there is an accompanying responsibility to evaluate the implementation process and the impact of the program.

There is a singular lack of curiosity about what happened to an innovation between the time it was designed and various people agreed to carry it out, and the time that the consequences became evident. (Fullan \& Pomfret, 1977, p. 330)

This study focuses on that time period, specifically with a description of the change process during the first year of implementation.

This study is a descriptive investigation of the implementation of a new instructional approach. The data 
include: description of the change from the perspectives of participants; information about the context and the implementation process; district, school, and teacher demographics; teacher self-reported implementation behaviors; and student self-reported behaviors and attitudes toward reading and writing. The contextual information includes organizational variables for the schools within the two districts included in the study. Information on the implementation process was acquired through staff interviews at the school and district levels. Evidence of implementation was collected in the form of questionnaire data describing teacher self-reported behaviors. Evidence describing behaviors and attitudes of students was also reported in the form of questionnaire data to provide a focus on student perspectives during the implementation process. Specifically, students' attitudes about reading and writing was explored and considered in relation to level of implementation reported by their teachers.

\section{BACKGROUND OF THE STUDY}

Because the Integrate Whole language approach represents a major contrast to traditional approaches in the definitions of reading and writing, and in the ways children learn and are taught, definitions of each approach are in order. A description of the contrast in approaches follows. 
Traditional Approaches

Traditional approaches to reading and writing or language arts instruction focus on student learning of skills and subskills in isolation of each other and outside of functional settings. Phonics instruction and use are promoted and reading aloud is a matter of being able to sound out the words. Spelling is taught with little regard for comprehension. Traditional approaches are generally guided by basal reader programs which are primarily subskill oriented rather than focused on literature or writing approaches to literacy learning (May, 1990).

\section{Integrated Whole Lanquage}

Approach

An Integrated Whole Language instructional approach has students learning through large meaningful selections of functional text. Much of this text was written by the students themselves. To put this another way, in Integrated Whole Language instructional approach uses relevant examples of print from students' lives for both reading and writing. "The central principle is that language is learned best when the learners focus is on its communicative use" (Goodman \& Goodman, 1986, p. 128).

\section{Contrast in Instructional}

\section{Approaches}

The traditional program in its approach to teaching the basic skills has isolated them in order to concentrate 
on the mastery of each skill before putting them together, while the integrated approach emphasizes a total whole Language context from the beginning. This contrast has significant implications for classroom teaching in terms of changes in instructional approaches, scheduling, materials, and student activities. These changes are reflected in the teacher questionnaire items of this study.

"A universal goal of reading instruction should be the fostering of positive attitudes toward reading" (Alexander \& Filler, 1976, p. 34). This study considers student attitudes toward language arts in the description of implementation of Integrated Whole Language instruction. Advocates of integrated Whole Language instruction point to outcomes such as love of reading, increased use of reading, increased expression through writing, as well as equivalent achievement gains. Many of these outcomes are reflected in the student questionnaire items for this study.

One of the major outcomes of our educational system is the development of lifelong readers (Gans, 1963), so both achievement and attitude are desired results of an instructional approach. The Integrated Whole Language approach is directed to both results (Norris, 1990), so it is important to commit research and development efforts to the approach.

This research project represents one aspect of such research concentration, the study of implementation of the 
Integrated Whole Language instructional approach as noted in this chapter.

\section{IMPLEMENTATION OF INSTRUCTIONAL APPROACH AS CHANGE}

A major change in educational institutions is curriculum implementation or implementation of a new instructional approach. There is a gap in the literature describing such changes with one exception. There is extensive documentation of the problems which characterize the implementation process (Virgilio \& Virgilio, 1984). When implementation is viewed as a change process the literature base is expanded. Much was been written about teacher resistance to change, especially related to the lack of success of implementations of curricular and instructional programs (McLaughlin, 1987). One view of teacher resistance is that teachers are oriented toward the concrete and practical and resistance is influenced by the ethics of practicality, situation, and cost (Doyle \& Ponder, 1977). Another view is that school-level features such as teacher collegiality, instructional coordination, administrator's role in change, and the process of program adoption determines whether teachers resist or adopt change (Huberman \& Miles, 1984; Little, 1987; Rosenholtz, Bassler, \& Hoover-Dempsey, 1986). A third view is that teachers' beliefs about how students learn and what they ought to learn has the greatest effect on teacher change (Tobin, 
1987). Within all of the literature is a recognition of the significance of the source of change, or the importance of who decides what changes will be made. The prominent views about teacher change and the significant influences are represented in the contextual factors described in this study .

This study describes the implementation of a new instructional approach in the context of a change process. Teacher descriptions of the implementation and reports of actual use of the instructional approach were collected and interpreted in the context of those factors which typically influence change. Factors such as school district demographics, the decision making process, administrative support, inservice training, the principal's role, and resource support concerning the implementation comprise the context description.

Implementation of a new instructional approach in a major curricular area, language arts, represents a significant educational change. There is a paucity of research literature describing implementation of new curricular or instructional approaches, but there is a wealth of studies describing factors which support or impede change in schools. Curriculum planning and development typically receive initial research attention and effort, but little or no regard is paid to studying implementation or evaluation (Virgilio \& Virgilio, 1984). 
Primary assumptions about change provide a framework for developing the research questions for this study. Those assumptions represent a change model developed for curricular change by researchers at the University of Texas (Hall, Wallace, \& Dossett, 1973). The include:

1. Change is accomplished by individuals, not institutions.

2. The change process takes time.

3. Change is highly personal and influenced by experiences, emotions, expertise, and skills.

4. Change is developmental growth in both feelings and skills in using a new program.

Those assumptions about change directed the research questions which guide this descriptive and exploratory study. To describe the implementation of an Integrated Whole Language instructional approach, the following questions are posed:

1. How do teachers and administrators describe the change related to implementation of the Integrated Whole Language approach? Are there individual and group differences in perceptions of the change?

2. How do teachers describe their language arts instruction during the first year of implementation of an Integrated Whole Language instructional approach? 
3. Are there differences between teachers, between schools, and between districts in the level of implementation?

4. Is there a relationship between teacher level of implementation and teacher characteristics (demographics)?

5. Is there a relationship between level of implementation and contextual factors in the educational settings (district differences, school differences)?

6. How do students describe their attitudes and behaviors related to reading and writing during the first year of implementation of an Integrated Whole Language instructional approach?

7. Is there a relationship between students' attitudes and behaviors and their teacher's level of implementation of an Integrated Whole Language instructional approach?

This study describes the implementation of an Integrated Whole Language instructional approach at the fifth grade level in two school districts. The description includes descriptions of change related to the implementation from the perspective of participants, teachers' reports of their approaches to language arts instruction, descriptions of the educational contexts with regard to presence or absence of factors supporting change, and students' reports of attitudes and behaviors related to reading and writing. To differentiate between individual, 
school, and district amount or extent of implementation, teachers' reports of their approaches to language arts instruction are compared with an "ideal profile" of the Integrated Whole Language instructional approach fully implemented. These comparisons quantify the teacher data and provide implementation scores. The implementation scores are then analyzed for relationships with teacher demographics, and within the contexts of implementation, that is, in relation to descriptions of individual schools and school districts. Research literature describing factors which support teacher change guides analysis of the contextual descriptions.

The teacher data include information regarding teacher understanding and use of the formal program of instruction.

We need to discover not only which teacher behaviors are effective, but also why teachers do or do not adopt recommended teaching practices. (Mohlman, Coldarci, \& Gage, 1982, p. 31)

This study extends the understanding of factors which influence teacher classroom adoptions, that is, how much implementation actually goes on "behind the classroom doors."

\section{DEFINITION OF TERMS}

Integrated Whole Language and traditional approaches are defined for clarity and understanding of the change represented in the implementation described in this study. The remainder of the terms used in this study have broad 
connotations in general use. They are defined specifically in relationship to their meaning in this study.

The Integrated Whole Language Arts Instruction: The teaching of listening, speaking, reading, and writing with opportunities for interaction of the language process in the holistic context of communication. Language is learned in the context of meaningful use, and from whole to parts. There is a natural relationship among the components of language. Students develop a proficiency with their previous oral language functioning together with written language (Goodman, 1986).

The Traditional Approach to Lanquage Arts Instruction:

A skills-based instructional approach with separate activities focusing on the skills and the subskills in isolation of each other and out of functional settings. Basal reading programs guide the teachers (Durkin, 1988). Separate reading and writing activities are used in the development of verbal skills: listening, speaking, reading, and writing. After practicing the separate skills for mastery, these are assembled and the total language is experienced (Durkin, 1983).

Implementation: Implementation consists or may consist of a change in behavior and attitude from an existing practice to a new or revised practice (Fullan \& Park, 1981). 
Context: Organizational factors (Sparks, 1988) which lead to the success of an instructional change, and include support from district, the principal, and the teachers themselves. The initial source of change, the politics involved in the decision making, school principal's role, financial support, the existence of available support services, and the training methods involved may be part of the context.

Student Self-reported Behaviors and Attitudes: student behaviors and attitudes for this study are defined as behaviors and attitudes related to reading and writing as activities and preferences self-reported by students.

Teacher Implementation Behaviors: Teacher implementation behaviors for this study are defined as behaviors related to implementation of a Whole Language instructional approach to include scheduling, strategies, and materials as self-reported by teachers.

\section{SIGNIFICANCE OF THE STUDY}

The results of the study provide information to both teachers and administrators about implementation of an instructional approach as a change process.

Only in the last ten years has curriculum implementation become a major concern of our educational system. This concern has resulted partially from the expenditures of millions of dollars on development and partially from the realization that relatively few new ideas make it behind the classroom door. (Loucks \& Lieberman, 1983, p. 126) 
This study extends understanding of the process of change in schools, specifically the change involved in implementing new approaches to instruction. There is already a knowledge base describing contextual factors which influence change, but there are gaps in the data on teacher implementation of change. This study expands the descriptions and begins to explain teacher differences. The data also have potential for influencing administrators in their decisions to bring about change, specifically in terms of the importance and kind of support provided to teachers.

\section{LIMITATIONS OF THE STUDY}

This study is confined to describing the implementation of a new instructional approach with a limited sample of fifth grade teachers and students from two school districts; an urban and a suburban district. The study includes an extensive contextual description to enhance the interpretability and usefulness of the information. The process of describing a formal adoption and implementation of an instructional program could be generalizable to other grade levels and content areas. However, specific implications in terms of student attitudes/behaviors and teacher behaviors may not generalize to other grade areas. The study is limited further by selfreport methodology. No attempt was made to verify data through observation. This limitation represents a decision 
to provide a larger sample of teachers and descriptions from two different school districts rather than observational data on a limited sample of teachers.

Additionally, this study focuses only on specific descriptions of the implementation process. There is no evaluation data, specifically student scores, for two reasons: the change process takes time (Hall et al., 1973) and collection of such evidence would be premature during the first year of implementation; and current assessment approaches in language arts are not well matched to content and process of the Integrated Whole Language instructional approach (Sanacore, 1990). Limiting this study to exploration and description is appropriate in view of the lack of direction in research literature on curricular and instructional change implementations and the newness of the Integrated Whole Language approach.

\section{INTRODUCTORY SUMMARY}

Educators continue to search for better ways to help students learn to read and write. When school districts initiate instructional change, it is important to study and describe the process. This study investigates and describes the change process in the context of an implementation of an Integrated Whole Language instructional approach at the fifth grade level. This study also explores potential student outcomes including increased number of books read, 
increased reading time, and preferences for reading which occur related to the instructional change. Additionally, the study investigates the relationship between student self-reported attitudes and behaviors and teachers' reported implementation behaviors.

\section{METHODOLOGY}

\section{Introduction}

The purpose of this study is to describe the implementation of a new instructional approach as a change process. The description includes participant perceptions of the change, and was placed in the context of school and district factors known to influence change. Additionally, this study explores the relationship between student selfreported attitudes and behaviors and teachers' reported implementation behaviors.

The change process was investigated using contextual data collected from historical records and interviews with teachers, school, and district staff. The historical information includes basic demographics such as district and school enrollments and their characteristics, philosophy, and management systems. Interviews generated more specific information regarding the implementation or change process and included questions about the decision making process, support for change, and communication related to the change (see Appendix A) . 
Data on teacher instructional behaviors was collected in the form of teacher responses to a questionnaire designed by the investigator (see Appendix B). The questionnaire focuses on type of instructional methodology and materials used, understanding of the Integrated Whole Language approach, inservice preparation, and scheduling data related to teaching reading, language, and writing. Profiles exemplifying "ideal" response patterns for Whole Language oriented teacher were generated by experts in the field of language arts instruction. Each teacher's response is compared with the "expert profile" to quantify implementation from the self-report data for this study. Those comparisons yielded implementation scores for each teacher.

Evidence of student attitudes and behaviors are measured by student responses to a questionnaire (see Appendix c). The questionnaire was designed by the investigator to probe the number of books read, the amount of time spent reading, and the level of preference for reading as an activity. Student responses are described in relation to their teachers' responses to explore the relationship between teacher behaviors and student behaviors and attitudes.

Research Design

The design of the study is exploratory and descriptive. Quantitative and qualitative methods are 
combined to describe the implementation process. Fifth grade teachers from two districts, one urban and one suburban, were surveyed regarding their implementation behaviors. Extensive descriptive data were collected to explore the change process in the context of specific schools and districts. In addition, data on student behaviors and attitudes were investigated for relations with teacher implementation behaviors. The design of this study called for a pilot study, the research study, and data analysis. A description of the sample for the research study and instrumentation for both pilot and research studies precedes the design information.

\section{Sample}

The sample consists of 27 fifth grade teachers and 651 students from two school districts. The two districts are a large (over 50,000 students) urban district and a medium size (under 10,000 students) suburban district. A random sample of five elementary schools from each district was selected. All the schools were asked to participate on a voluntary basis. Only one school (in the suburban district) elected not to participate. The fifth grade teachers and students from each of these schools were also asked to participate in the study. 
Instrumentation

Student and teacher questionnaires were developed to investigate teacher self-reported implementation behaviors and student self-reported behaviors and attitudes. Teachers were asked to identify the type of instructional methodology and materials used, number of inservices attended, and amount of time spent teaching language arts. Students were asked to identify the number of books read, amount of time spent reading, and their preference for reading over other activities. In addition, a protocol for interviewing teachers and administrators at both school and district levels was developed. The interview questions reflected the organizational factors known to influence change. The protocol format assured consistency of interviews.

\section{Procedures}

The pilot study was conducted in one school with two fifth grade teachers and their students for the purpose of clarifying the questionnaires and rehearsing procedures. The interview protocol was also tested for clarity and ease of eliciting responses.

After revising the instruments and the interview protocol, the main research study was conducted with a random sample of fifth graders and their teachers in nine schools; five in the urban district and four in the suburban district. 
The data were collected from the students and teachers by the investigator. The contextual interviews were conducted by the investigator and a research assistant.

\section{Data Analysis}

The data were analyzed to describe the implementation of a new instructional approach as a change process in the context of district, school, and teacher characteristics and factors with potential to influence change. The contextual data were organized and presented in mini cases of the two school districts and the individual schools. From there the data analysis procedures were organized according to the research questions listed previously.

In response to Question 1, "How do teachers and administrators describe the change related to the implementation of the Integrated Whole Language approach?" and "Are there individual and group differences in the perceptions of change?" the data are qualitative. Descriptive analysis documents the participants' perceptions of the change and the differences between individuals and groups (schools, districts).

In response to Question 2, "How do teachers describe their Language Arts instruction during the first year of implementation of an Integrated Whole Language instructional approach?" teachers' responses to the questionnaire (see Appendix B) are analyzed descriptively. 
Before responding to Question 3, individual teachers' responses to the questionnaire are quantified by comparing them with the "ideal profile" of an Integrated Whole Language teacher. This analysis yields implementation scores with which to describe responses to Question 3, "Are there differences between teachers, between schools, and between districts in the level of implementation?" From there, a frequency distribution displays the differences in implementation scores between teachers and schools. To establish the presence or absence of significant differences between the two districts, a $t$ test procedure was used. In response to Question 4 , "Is there a relationship between teacher implementation score and teacher characteristics (demographics)?" the analysis consists of chi-square and $t$ test procedures depending on the scale of measure for the demographic data.

In response to Question 5, "Is there a relationship between implementation scores and contextual factors in the educational settings (district differences, school differences)?" the mini cases of schools and districts provide a context for descriptive analysis of school and district implementation scores.

In response to Question 6, "How do students describe their attitudes and behaviors related to reading and writing during the first year of implementation?" a descriptive 
analysis of students' responses to the questionnaire items was conducted.

In response to Question 7, "Is there a relationship between students' attitudes and behaviors and their teachers' implementation scores related to an Integrated Whole Language instructional approach?" the analysis was directed to exploring the differences in students' responses to the questionnaire items using differences in teachers' implementation scores. The analysis employs chi-square and Pearson Product Moment procedures.

\section{Preview of Results}

It was predicted that teachers would vary in their descriptions of the change related to implementation and in level of use of the Integrated Whole Language instructional approach. It was further predicted that the variation would be related to differences in teacher characteristics. It was also predicted that the schools and districts would differ in perceptions of the change related to implementation and in school-wide and cross-district level of use of the instructional approach at fifth grade. It was further predicted that there would be a relationship between that level of implementation and contextual factors in the educational settings related to change. It was further predicted that there would be a relation between teacher level of implementation and student reported behaviors and attitudes. 
SUMMARY

"Continuing inquiry into processes of educational change are essential if school improvements efforts are to surpass their current levels of modest impact" (Leithwood \& Montgomery, 1982, p. 157). This study provides a comprehensive description of the change process. The implementation of an Integrated Whole Language approach at the fifth grade level is examined in the context of school organizational factors known to influence change and on the basis of self-reports by teachers, students, and administrators. In addition, this study investigates the relationship between teachers' implementation behaviors and students' attitudes and behaviors. Potential student outcomes related to the instructional change are also explored. These outcomes include: a preference for reading over other activities, increased amount of books read, and increased reading time.

This study employs a blend of qualitative and quantitative methodologies. The decision to provide extensive descriptive data is an attempt to explore all the variables that play a role in the change process.

\section{DISSERTATION FORMAT}

This chapter provides rationale for conducting this study to describe the implementation of an Integrated whole Language approach at the fifth grade level with descriptions 
of the problem, significance, potential contributions, and literature background. The research questions, methodology and limitations of the study are summarized.

Chapter II provides an extensive review of research and development literature in the areas of language arts curriculum and instruction, specifically describing the contrast between traditional approaches and the Integrated Whole Ianguage approach. The knowledge base regarding implementations of new curricular and instructional approaches, the change process in education, and organizational factors which influence change are reviewed. In addition, research studies supporting the relationship between teacher behaviors and student behaviors and attitudes are provided.

Chapter III presents the methodology with descriptions of the sample and instrumentation. The procedures are presented for the pilot study, the research study, and for the data analysis.

Chapter IV provides an overview of the results of the data analysis. From there, the organizational factors and the demographics obtained through interviews are presented in mini cases of the districts and schools. Results of the questionnaire data analysis are presented in responses to each of the research questions.

Chapter $V$ describes conclusions which emerge from the results of the study. Implications for teachers, for school 
principals, and for district-level administrators regarding curricular and instructional implementations, district and school policy, and staff development are developed from the conclusions. Recommendations for future research and development extend the implications of this study. 


\section{CHAPTER II}

REVIEW OF THE LITERATURE

\section{INTRODUCTION}

\section{Study Purpose}

The purpose of this study is to describe the implementation of a major curriculum change (at the fifth grade level) in two different school district settings; an urban district and a suburban district. The major curriculum change examined is the shift from a traditional reading and language arts program to an Integrated whole Language program. The implementation of this change is examined on the basis of self-reports by teachers, students, and administrators and is described in the context of organizational factors in schools that have typically influenced change: school district demographics, decision making-process, administrative support, inservice training, the principal's leadership role, and resources available. Additionally, the study investigates the relationship between teacher self-reported implementation behaviors and student self-reported attitudes and behaviors. 


\section{Chapter Contents}

This chapter provides a review of the literature to illustrate the need for and importance of this study. The review of the literature begins with definitions of the contrasting instructional approaches involved in the curriculum change. The differences between approaches are described with support from the literature. The literature on implementation is viewed in light of the change process, accompanied by descriptions of the contextual factors that have typically influenced change. The final body of literature provides a review of investigations of the relationship between teacher self-reported behavior and student self-reported attitude and behaviors.

\section{APPROACHES TO READING AND LANGUAGE ARTS INSTRUCTION}

Because the Integrated Whole Language approach represents a major contrast to traditional approaches in the definitions of reading and writing, and in the ways children learn and are taught, definitions of each approach and the contrast between approaches are described. These descriptions are provided to support the quality of the change in instructional approach, that is, a significant shift in the teaching/learning paradigm for language arts, that is the focus of this study. The contrast descriptions are supported by research conclusions and insights. 
Traditional Approaches to

Instruction

Traditional approaches to reading and writing or language arts instruction focus on student learning of skills and subskills in isolation of each other and outside of functional settings. Phonics instruction and use are promoted and reading aloud is a matter of being able to sound out the words. Spelling is taught with little regard for comprehension. Traditional approaches are generally guided by basal reader programs which are primarily subskill oriented rather than focused on literature or writing approaches to literacy learning (May, 1990).

Traditional skills-based teachers often rely on basal readers and the accompanying teachers guides (Anderson, Hiebert, Scott, \& Wilkinson, 1985). Basal readers are organized sequentially, taking the teacher and student through one skill lesson to the next. Syntax, semantics, graphophonics, and background cues are taught through separate "skill lessons" and worksheets. Any creativity in approach or expansion beyond a prescribed set of skills are at the discretion of individual teachers. As Durkin (1983) articulates, "What is important but not in the manual will have to be added by the teacher" (p. 360).

\section{Integrated whole Language} Approach to Instruction

An Integrated Whole Language instructional approach has students learning through large meaningful selections of 
functional texts. Reading and writing are viewed as communicative acts. Learning becomes a social process of communication between students and teacher, students and students. Students author much of the text used in the classroom. Learning in a Whole Language classroom recognizes the fact that students come to school with a base of language and communication skills gained from their environment outside of the classroom. The Integrated whole Language instructional approach uses relevant examples of print from students' lives for both reading and writing. "The central principle is that language is learned best when the learners' focus is on its' communicative use" (Goodman \& Goodman, 1986, p. 128).

The Whole Language teacher is an active participant in the students' learning process. They often read and write with the students. The environment they create is a reflection of what it means to be "literate," facilitating learning with demonstration and response as their tools of instruction (Stephens, 1991).

\section{Contrasts Between Approaches}

The traditional approach relies on teaching basic skills in isolation in order to concentrate on the mastery of each skill before putting them together. The Integrated Whole Language approach emphasizes a total Whole Language context from the beginning. In other words, reading, writing, listening, and speaking are integrated in 
activities that represent "real life" daily use of communication.

A study conducted by Watson, Crenshaw, and King (1984) illustrates the extreme differences in the theoretical bases of these approaches. The purpose of the study was to observe and describe two reading instruction procedures stemming from two different theoretical influences. Two teachers participated, one traditional skills oriented teacher and one Whole Language oriented teacher. Their stated instructional base and theoretical orientations were measured using the Theoretical orientation to Reading Profile (TORP), developed and validated by DeFord (1978). Data were collected from video tapes, transcripts, and teacher journals. The results were analyzed using these questions as guides:

1. On what unit of our language and linguistic system did the teacher focus the children's attention?

2. What aspects of reading were emphasized?

3. Was the reading contingent on the student, teacher, or material?

4. What attitude toward reading specific text did the teacher encourage?

These questions reflect the practical and philosophical differences between the approaches. The results showed that in every category the teachers adhered closely to their theoretical model and illustrated the 
diametric opposition of the two instructional approaches. Examples of their statements illustrate well the differences between teacher thinking and instruction.

The skills teacher strongly agreed with the following statements:

1. An increase in reading errors is usually related to a decrease in comprehension.

2. When children do not know a word, they should be instructed to sound out its parts.

3. Reversals (e.g., saying "saw" for "was") are significant problems in the teaching of reading.

4. Phonic analysis is the most important form of analysis used when meeting new words.

5. It is important for a word to be repeated a number of times after it has been introduced to insure that it will become a part of sight vocabulary.

The Whole Language teacher strongly agreed with the following statements:

1. When coming to a word that is unknown, the reader should be encouraged to guess based on meaning and go on.

2. It is not necessary for a child to know the letters of the alphabet in order to learn to read.

3. Flashcard drill with sightwords is an unnecessary form of practice in reading instruction.

4. If a child says "house" for the written word "home," the response should be left uncorrected. 
5. It is not necessary to introduce new words before they appear in the reading text.

The study by Watson, Crenshaw, and King (1984)

illustrates the extreme contrasts between the two

approaches. Similar differences in philosophy and practice have been found by other researchers (Colvin, 1991; Siera \& Combs, 1990). In addition, a study by Freppon (1988) questions children's concepts of the nature of reading in skills-based and Whole Language classrooms. Freppon's study illustrates the opposition of the two approaches through children's responses. Burke's (1987) Reading Interview was used to question first grade children about reading and readers. Two Whole Language classrooms and two skills-based classrooms were selected. From there, 24 randomly selected average readers were chosen to participate.

The differences found in Freppon's (1988) study were correlated with instruction. Students in the skills-based classroom said they were good readers because they knew a lot of words, but only $50 \%$ felt understanding a story and getting the words right was important. In contrast, $90 \%$ of the Whole Language group felt it was important to understand and get the words right when reading. They also identified themselves as good readers because they read a lot of books. Freppon also noted from the results and from observation that the Whole Language students seemed to have grasped the idea that reading is a language process. The Whole Language 
group was more involved as "readers," whereas the skills-based group did not seem to understand the idea of reading as communication. A previous study by Dillon and Searle (1981) also concludes that children's classroom language reveals the teachers' theoretical base. In the study described here, students were asked about reading as a choice and time spent reading to explore similar effects of the Whole Language instructional approach.

The two instructional approaches have been described and studies of their contrasts demonstrate that they are in diametric opposition. The implementation of an Integrated Whole Language approach constitutes a major change in language arts instruction and thus is the focus of this study.

Rationale for studying Integrated Whole Language Approach

The Integrated whole Language approach to language arts instruction is being adopted and implemented as a formal program of instruction in many urban and suburban school districts throughout the United States. These adoptions have focused attention upon recent research findings describing how children learn to read and write, at a time when there is support for more time spent on reading in schools (Lehman \& Crook, 1988). In 1985, recommendations of the Commission on Reading suggest that teachers rely more on comprehension and less on skills, that students should be 
required to do more independent reading and writing, and that schools should foster an environment that supports reading (Anderson et al., 1985). Since the release of the Commission's report, these research-based suggestions have provided an impetus for both teachers and administrators to review their language arts programs from a new perspective, that of functional use as communication.

The Integrated whole Language approach represents a change brought about by pressures from within the education profession (Anderson et al., 1985) and by societal pressures (Harp, 1988; Rowan, 1990). As a curricular and instructional approach, it is probably the most widely published and extensively articulated innovation (Dillon \& O'Brien, 1992). The attention being given to the Integrated Whole Language approach directed this investigator to study and describe its implementation as a highly significant change.

\section{IMPLEMENTATION AS CHANGE}

A major change in educational institutions is curriculum implementation or implementation of a new instructional approach. There is a paucity of literature describing such changes. Typically there is concern in the beginning (planning) and in the end (evaluation); however, the actual implementation is unattended in most studies. An exception is the extensive documentation of the problems 
which characterize the implementation process (Virgilio \& Virgilio, 1984). There is also rich research description of the factors which support or impede implementation (sparks, 1988). However, when implementation is viewed as a change process, the literature base is expanded. There is a broader base of research insights related to change. Yet, again much of the work is in the context of the lack of success of implementations of curricular and instructional programs related to teacher resistance (McLaughlin, 1987). Researchers and developers attach a utilitarian purpose to the study of implementation problems.

Understanding the developmental aspects of change helps us design implementation efforts that are long-term and that anticipate teachers' questions and problems. (Loucks \& Lieberman, 1983, p. 131)

There are varying perspectives concerning teacher influence on change. One view of teacher resistance to change is that teachers are oriented toward the concrete and practical (Doyle \& Ponder, 1977). Their resistance is influenced by the ethics of practicality, situation, and cost. Another interpretation is that school-level features such as teacher collegiality, instructional coordination, administrator's role in change, and the process of program adoption determine whether teachers resist or adopt change (Huberman \& Miles, 1984; Little, 1987; Rosenholtz, Bassler, \& Hoover-Dempsey, 1986). A third perspective is that teachers' beliefs about how students learn and what they ought to learn has the greatest effect on teacher change 
(Doyle \& Ponder, 1977; Tobin, 1987). Within all the literature is a recognition of the source of change, or the importance of who decides what changes will be made.

A global view of teacher change is the Concerns-Based Adoption Model (CBAM) developed by researchers at the University of Texas (Hall, Wallace, \& Dossett, 1973). The CBAM was developed to conceptualize teachers' needs and uses of different change programs. It has since become a curricula change model which has directed planning for change, the monitoring of change and interpretation of studies of change. The assumptions inherent in the model directed the design of this study. They include:

1. Change is accomplished by individuals not institutions.

2. The change process takes time.

3. Change is highly personal and influenced by experiences, emotions, expertise, and skills.

4. Change is developmental growth in both feelings and skills in using a new program. These primary assumptions about change provide the foundation for six research questions for this study.

A more recent study of the adoption of a whole Language philosophy toward literacy instruction adds further support to the assumptions about curricular change and to the design of this study (Nistler \& Shepperson, 1990). Teachers in a Texas elementary school recorded concerns and 
progress in journals and responded in interviews and on surveys to the change. Their "voices" confirmed change as a process and a "highly personal experience." The study directs future studies of implementation to approaches with a broad scope, including teacher practice, student views, and support opportunities. The study described here responds to the directive of Nistler and Shepperson's 1990 study .

\section{APPROACHES TO STUDYING IMPLEMENTATION}

In order to understand the process being studied in this dissertation and to provide a context for interpreting the change to be investigated, it is imperative to provide a summary of the knowledge base related to implementation. Implementation consists or may consist of a change in behavior and attitude from an existing practice to a new or revised practice (Fullan \& Park, 1981). "In other words, implementation is not simply an extension of planning and adoption processes. It is a phenomena in its own right" (Fullan \& Pomfret, 1977, p. 336). There is a critical need to study implementation because it generally involves significant expenditures of time, money, effort, and planning. Educators cannot be certain or understand what has occurred in implementation, unless they try to describe it quantitatively and qualitatively. It is also necessary to do this in order to find out why many educational changes 
fail. The lack of concern for implementation may result in the process being ignored. By not addressing these issues it is impossible to relate specific learning to specific determinants in the implementation process (Fullan \& Pomfret, 1977; Loucks \& Lieberman, 1983). When implementation is studied, the data provides direction and guidance for future implementations.

\section{Measuring Implementation}

One barrier to understanding successful implementation has been lack of description and discussion of improvement efforts from the perspective of the teacher and school. (Loucks \& Lieberman, 1983, p, 127)

Most implementation studies have relied on "reported use" (Persall, 1972; Washington University, 1970), learning outcomes, or determinants (Bohn \& Raun, 1970). Fullan and Pomfret (1977) note that many studies have confused implementation with other aspects of the change process such as adoption or the decision to use an innovation.

\section{Measuring Implementation} Through Determinants

"The confusing of determinants of implementation with implementation itself" (Fullan \& Pomfret, 1977, p. 338) is another example of the direction which the research on implementation has taken. A classic example is the study by Butt and wideen (1974). They attempt to assess the degree of the implementation of a province-wide inquiry oriented junior high school science curriculum. Fullan and Pomfret 
(1977) argue that the measures used by Butt and wideen refer more to determinants of implementation than implementation itself. In their study, implementation was measured by a scale developed by researchers Butt and wideen. The Arbitrary Implementation Scale (AIS) consisted of 28 items in five categories. The scale was judged by experts who concluded that it reflected the new curriculum in use. The five categories of items were:

1. In-service education.

2. Knowledge, acceptance, and agreement within the philosophy, aims, and objectives of the curriculum.

3. The self-perception of teaching ability for the curriculum.

4. The extent of to which certain factors helped or hindered implementation.

5. Specific practices in teaching and evaluation. Fullan and Pomfret (1977) argue that only three of the AIS's five categories measure implementation $(2,3$, and 5) and that the other two refer to determinants ( 1 and 4 ). Fullan and Pomfret further argue that "this confusion makes it difficult to conceptualize implementation and to ascertain the factors affecting it" (p. 338).

Measuring Implementation Through Achievement

Another approach to studying implementation is through achievement (Norris, 1990; Phillips, 1990). Learning 
outcomes have been widely used as a measure of implementation. Assessing the outcomes of a program in isolation from its environment ignores the fundamental character of the implementation process (McLaughlin, 1987). These outcomes are most likely the motivation for educational changes, but Fullan and Pomfret (1977) argue that this is not a valid measure of implementation because of the limits of focus. These approaches may only reflect certain skills and not full implementation (Biological Science Curriculum study, 1970). Additionally, most studies relying on achievement as evaluation do just that. There is little discussion of the process of implementation. An example is a study by Phillips (1990). Phillips' study examines the effectiveness of a program to improve the reading/vocabulary skills of an ability-grouped fifth grade class of "low achievers" through the implementation of a literature-based whole Language approach. The approach is described, but never any mention of the process of implementation, the support provided for implementation, teachers' implementation behaviors, or the degree of implementation. These factors are assumed through the evaluation. The evaluation consisted of a comparison of IOWA test scores, those administered before the implementation and those administered one year after the implementation had begun. Although the results showed significant gains (17 months in reading, 16 months in 
vocabulary, and 7 months in spelling), these results could be attributed to a number of variables, implementation being only one of the possibilities.

The process of implementation must be assessed differently. When schools and teachers are inundated with new reforms, they may resort to "teaching to the test" if this practice of measuring implementation continues (Wise, 1988). In the case of reading, they no longer teach important reading skills, but only those measured by achievement tests. Measurement of learning outcomes through traditional achievement tests would be an especially inappropriate approach to studying the implementation process of this study. Current assessment approaches are not well matched to content and process of the Integrated Whole Language approach, so they cannot be used to assess implementation in this study (Sanacore, 1990). This study focuses only on specific descriptions of the implementation process as change and does not include evaluation data.

Measuring Implementation Through "Reported Use" Methodology

The final problem in studying implementation of an instructional approach noted by Fullan and Pomfret (1977) is the limitations of a "reported use" methodology. They caution researchers that this may only reflect an "attitude" of implementation not implementation itself. A study by Moore, Wideman, and Dilling (1984) attempts to assess 
teachers' level of use of two selected curriculum guides. They addressed the validity of the teacher level of use scale for the "self-report" method. The level of use is assessed for each dimension of the Scarborough Profile chart (defined steps of progressively more consistent and effectively integrated teacher actions) based on the research of Hall et al. (1975); Heck, Stiegelbauer, Hall, and Loucks (1981); and Leithwood and Montgomery (1982). The profile chart consisted of a five point level of use scale including levels for: (a) non-use, (b) initial preparation, (c) mechanical use, (d) routine use, and (e) refinement and integration.

Findings indicate that the curriculum guides had been implemented at level three or higher by the majority of teachers who taught grades one, five, and six. Barriers to implementation were: (a) insufficient time for reading and internalizing, (b) lack of materials or equipment, (c) insufficient communication amongst teachers, (d) work overloads, (e) other priorities, (f) lack of team planning, and (g) insufficient inservice training. The findings of Moore et al. (1984) were presented with a recognition of the limitations of self-report methodology. Validity of the self-report method was also addressed. Factors which impede validity were possible misinterpretation of questions, misinterpretation as teacher evaluation, and the potential for teachers to be adverse to reflection on the questions. 
Since the study relies exclusively on self-report methodology, interviews were conducted with a randomly selected group of teachers to establish validity. The inquiry investigates whether "a self-report questionnaire completed independently by teachers can provide a level of use portrait which is congruent with actual teaching behaviors?" The interview data provide a concurrent validity check.

The teachers in the Moore et al. (1984) study were also interviewed for their interpretation of the curriculum guides. Their interpretations had the effect of either supporting implementation or impeding implementation. Their interpretation also revealed their definition of the curriculum approach. Taking a cue from the research of Moore et al., the study described here begins with exploration of how teachers define the Integrated Whole Language approach. For the study described here, the self-report methodology represents a decision to provide a larger sample of teachers and extensive contextual descriptions from two different school districts rather than observational data on a limited sample of teachers.

Research of implementation has begun to concentrate more on the people and the environments involved. When teachers are asked to make changes in their teaching approaches, researchers have determined that it is critical to ask how teachers respond (Goodlad, 1975; Sarason, 1971). 
Another focus of current investigations is "how" the change processes are described by the teachers (Gibson, 1973; wolcott, 1977). Limiting this study to exploration and description is appropriate in view of the dissatisfaction with major approaches to measuring implementation (Hall \& Loucks, 1978; Sieber, 1979). The study described here does, however, incorporate current interest and recommendations for focus on individuals and context of implementation.

\section{STUDIES OF CHANGE}

This study describes the implementation of a new instructional approach conceptualized for this investigation as a change process. Teacher descriptions of the implementation and reports of the actual use of the instructional approach were collected and interpreted in the context of those factors which research has shown to influence change. This study focuses on factors such as school district demographics, the decision making process, administrative support, inservice training, the principal's role, and resource support concerning the implementation. These factors comprise part of the context description of this study.

\section{Contextual Factors Affecting}

Change

The work of Jenks (1970) was helpful in identifying some of the contextual factors for this study. The purpose 
of Jenks' study was to determine the factors affecting the adoption of change. Predictor variables were used in explaining the rate of adoption of an innovation by a group of elementary school teachers. Fullan and Pomfret (1977) define "adoption" as the decision to use an innovation, differentiating it from implementation, the actual use of an innovation. Having acknowledged this, Jenks' study provides one framework for viewing change.

Jenks' (1970) study includes 84 participants in 19 schools, representing 10 districts. The teachers participated in the teacher education program of a science inservice project in Austin, Texas. They attended 11 training sessions over a seven month period. The teachers were taught in the same manner in which they would be expected to teach their students. They were asked to begin teaching the new program when they felt they understood the approach and were comfortable with the materials. Once the study began, they administered a competency measure to their students upon completion of each teaching exercise.

An adoption model (Jenks, 1970) was developed based on Diffusion of an Innovation by Rogers (1965). The model suggests stages of adoption which include:

1. Awareness: exposure to approach.

2. Interest: initial interest in the approach, not yet judged. 
3. Evaluation: teacher's mental application of the approach.

4. Trial: the use of the approach on a small scale in the classroom.

5. Adoption: represents consideration of the trial results and implies acceptance of the use of the process approach.

These stages of adaption may emerge from the responses of teachers to the research questions of the study described here. In Jenks' study, the predictor variables were personal or individual adopter characteristics, informal or peer group relationships and interactions, and formal organizational influence. Multiple linear analysis was employed to test for relationships between the criterion variable (rate of adoption) and the predictor variables (personal, informal and formal organizational). The strongest predictor variable was formal influences. These included faculty assessments of actual influence of principal, of ideal influence of principal, school enrollment, and grade level taught. This influence may also be seen in the descriptive data of this study. The second strongest predictor variable in Jenks' study was personal influences. However, none of the teacher characteristics reached the level of confidence. Three personal variables or teacher characteristics did show a relationship to grade level taught. These characteristics included recency of 
teacher's educational training, teacher's response to necessity for changing methods, and number of schools the teacher had served in. A number of these same demographic variables are included in the study described here. The informal peer group variables were the least influential, although relationships were found. They include the inservice teacher's status as a communicator of professional advice, inservice teacher's status as an influential faculty member, and the mean adoption ratios of a school compared with the number of inservice teachers from that school (involvement ratio). The study described here investigates some of the same peer group variables for influence on implementation of the Integrated Whole Language approach.

Jenks (1970) argues that the lack of influence of peers is because elementary school teachers have little time for interaction with other teachers and staff members. As mentioned earlier in the review of the literature, this was also found to be a barrier to implementation by Moore et al. (1984). When it is present, teacher collegiality appears to have positive effects on curriculum implementation (Little, 1981). Cohen (1981) collected questionnaire data from teachers in 16 elementary schools and found significant correlations between teaming arrangements and teachers' aptitude to accommodate new curriculum.

The complexities introduced by a new curriculum create one compelling reason for teachers to work 
together; an even more complex challenge it appears, is to examine and refine the existing curriculum and instruction of a group and to select and implement improvements on a continual basis. (Little, 1987, p. 495)

This study examines peer influences and extends the rationale of Jenks' argument because the sample consists of elementary school teachers.

A possible explanation for Jenks' (1970) finding that grade level taught was a significant variable, is that a formal science curriculum is normally initiated in the fourth grade. Teachers in the upper grades were already using traditional science methods (reading) and might have found the new approach (non-reading) "incompatible with their usual methods" (p. 199). Teachers in the lower grades did not have this experience, therefore they were probably more open to the approach. Another factor which might have contributed to this finding is that the materials used in the lower grades $(1-4)$ were researched more thoroughly than those in the upper grades (5 and 6 ). Jenks (1970) also adds that higher ratios of adoption in schools with smaller enrollments could be explained by a higher professional-to-pupil ratio. School size is a consideration in the study described here. Additionally, a principal in a smaller school would be able to provide more interaction and supervision with less teachers. A non-supportive principal was found to be a factor in schools with low ratios of adoption, as conversed by the personnel 
at the Science Inservice center. "The results of this study indicate that the principal should be considered in any effort to implement innovation" (p. 202). Jenks stresses the need for more studies to determine influence and power as predictor variables. His study provides a beginning framework for viewing change. The study described here uses a similar framework for the design and methodology to describe the implementation of an Integrated Whole Language approach.

Mechanisms Within Schools Affecting Change

Additionally, the work of Doyle and Ponder (1977) contributes to the design and methodology of this study. They describe an approach for effective change strategy based on the knowledge of the inherent mechanisms which operate in schools. "The purpose was to build a conceptual framework for understanding the way practicing teachers react to change proposals" (Doyle \& Ponder, 1977, p. 2). They suggest: (a) anecdotal records and other descriptive material gathered over a two year period, and (b) available evidence from existing studies of innovation projects, used to augment the descriptive records. The analysis consisted of interpretive categories and hypotheses to account for events and processes in the descriptive data. The study was based on description and explanation. Three questions were raised: 
1. What is the practicality ethic? (definition)

2. What factors shape the decision making frame of reference? (environmental)

3. Why is the practicality ethic such a potent force in school change? (analytical)

The nature of the practicality ethic is that although schools are bureaucracies, teachers are primarily autonomous in their work (Dreeben, 1973; Loucks \& Lieberman, 1983). Doyle and Ponder (1977) argue that when innovations are undertaken, this autonomy is reduced. "Innovation projects, in other words, generate a set of control mechanisms which are typically absent from the normal teaching environment" (Doyle \& Ponder, 1977, p. 3). Fullan (1972) observes that when innovations occur and the control mechanisms are apparent to teachers they are usually viewed as "power-coercive." This may be overridden when teachers view innovations as practical. They perceive potential consequences when they are attempting to implement a change proposal. Those perceived as impractical receive less consideration unless control mechanisms, such as those that frequently accompany innovation projects, make teacher decision making superfluous. When the consequences are weighed and are perceived practical, the change is given more consideration.

Doyle and Ponder (1977) created three criteria for their study: instrumentality, congruence, and cost. 
Instrumentality means the change must be described to teachers in terms which depict "classroom contingencies." The assumption that teachers can or will take program objectives and interpret them into new and appropriate behavior patterns is an inaccurate assumption, and is often a barrier to implementation (McLaughlin, 1987). The study described here considers how the change is translated to teachers and explores the support provided to teachers for understanding the approach.

Congruence for Doyle and Ponder (1977) is whether or not the change proposal matches classroom conditions. Do the procedures fit the way the teacher normally conducts classroom activities. Those that do not are viewed as impractical. The student outcome or reaction is weighed as the practicality issue is judged (McLaughlin, 1987). An example given is an innovation that works in an upper-middle class suburb will probably be perceived as "impractical" by teachers in an inner city school. Teachers also consider both the origin of the proposal and the person presenting the innovation. With congruence, teachers also weigh the compatibility of the program with their own self-image and the way in which they prefer to interact with students. They see the benefits of the innovation but feel it damages their teacher/student relationship. This study investigates the source of change and describes the individuals involved in the decision making. The influence of teacher self-image 
and preferences emerges from the teachers' responses to this study's research questions.

The final criterion presented by Doyle and Ponder (1977) is "cost." Whether the investment justifies the return is an implementation consideration in adoption (Stephens, 1974). This refers to the amount of effort needed to implement a new program. Due to the fact that educational changes usually require organizational changes, cost is generally high (Loucks \& Lieberman, 1983).

There is an understanding within the practicality ethic that change takes place over time and these factors will vacillate as implementation occurs. Doyle and Ponder (1977) add insight to the largely neglected feature of the innovation process and offer the practicality ethic as an interpretive tool for unraveling teacher decision making processes. It is a useful lens for viewing and understanding how the change process works within the context of implementation. The study described here explores whether the practicality ethic emerges from teachers' thinking.

\section{External Factors Affecting Change}

"Clear goals, well specified statutes, and effective authority are important external policy variables" (Elmore \& Mclaughlin, 1982, p. 174). These external factors are most important in the initial stages of implementation. Afterwards they recede in importance and "internal factors 
such as commitment, motivation, and competence dominate" ( $p$. 175). However, motivation or will is influenced by factors largely beyond the reach of policy. The inherent pressures, authority struggles, and stability of the environment can influence implementor willingness intensely (Yin, 1981). The essence of implementation is that "change ultimately is a problem of the smallest unit and is transformed as individuals interpret and respond to it" (McLaughlin, 1987, p. 174).

The Role of Administrator in

the Change Process

Rowan (1990) notes that an important reform initiative during the eighties was spurred by concern for low student achievement. That initiative advocated a decrease in bureaucratic controls in education and the creation of working conditions in schools to enhance the commitment and expertise of teachers.

Lack of bureaucratic controls has led to a more democratic style of management of schools. By relying more on the voice of teachers for decisions on implementation, the likelihood of success is increased (Berman \& McLaughlin, 1978; Louis, 1981). The assumption underlying this change is that when teachers are involved in decision making, their involvement enhances their commitment to the decision (Conley, Schmidle, \& Shedd, 1988). Teacher involvement in decision making does not guarantee success if it is not 
accompanied by other factors. The research points to a need for administrative support as well as pressure for the change process to ensure successful implementation. "Pressure is required in most settings to focus attention on reform objectives; support is needed to enable implementation" (Mclaughlin, 1987, p. 173).

Current research acknowledges the pivotal role of the principal in the implementation process. The principal's role has changed from that of an administrative role to include an instructional role (Virgilio \& Virgilio, 1984). Administrators must be ready to assist teachers as facilitators of change.

It is not entirely clear which behaviors of a principal are most supportive, but two which emerge as effective are critical: reminders that use of the new curriculum is a school priority, and informal encouragement and interest. (Loucks \& Lieberman, 1983, p. 132)

Stallings and Mohlman (1981) conducted a study of the relationship between school policy, leadership style, teacher change, and student behavior in eight secondary schools. Data were gathered through student observations, student and teacher questionnaires, student absence records, observations of the physical environment, and interviews with the principals. In the study, all the teachers participated in the Stalling's Effective Use of Time Training Program. Results of the study related to the principal's role are: 
1. In schools where policy and rules were clear and more consistently enforced, teacher morale was higher and there were fewer classroom intrusions; a lower absence rate, less misbehavior and more time spent on task.

2. In schools with more administrative support and services and fewer burdensome activities, there was less classroom misbehavior.

3. In schools where the principal was more collaborative and respectful, teachers had higher morale and students perceived teachers and students as more friendly.

4. In schools where the principal was more supportive, more teachers implemented the training program.

5. In schools where the principal/administration made the policies and rules clear, more teachers changed their classroom behavior as recommended by the program.

When the principal assumes an active role as a facilitator, it is generally reflected in the school environment and it influences those within it. That active role takes the form of collaborator, interacting respectfully and positively among teachers and students. This role is investigated in the study described here. Besides attending to administrative duties, the principal as an instructor and collaborator can enhance implementation. The principal must be ready to assist teachers in their needs and in their assessment of their students' competency and needs. The principal must aid 
teachers in their selection of materials, ensure that adequate inservice is provided, and arrange for the arrival of materials and/or equipment prior to implementation (Virgilio \& Virgilio, 1984). As noted earlier in the review of the literature, Moore et al. (1984) find inadequate inservice and lack of materials represent barriers to implementation. Throughout the implementation process, communication must remain open to allow for needs to be expressed and ideas to be discussed and digested. The principal is the facilitator of an environment that is conducive to communication. However, the actual implementation of an innovation is done by teachers (Huberman \& Miles, 1984). Acknowledgement of both administration and teacher roles directed the methodology design of this study.

TEACHERS AND CHANGE

Teachers were often diagnosed as "resistant to change" and even referred to as simply lazy when they ignored curriculum change (Mclaughlin, 1987). Doyle and Ponder (1977) point to a "growing body of descriptive studies which indicate that the actual amount of change in schools falls significantly below expectations" (p. 1). They point to the fact that most research relies on descriptions of teacher attitude, teacher competence, or teacher characteristics as explanations for failure. This study addresses these 
possibilities by looking at implementation as change within the contextual factors which explain differences in implementation. This research emphasis deflects the blame or the credit to influences which either support or block teachers. However, a review of research describing teacher influence is in order as a rationale for the design of this study. The research provided an impetus to conduct this investigation and to approach implementation as a change process within the context of influences.

\section{Teacher Characteristics}

A study by Bohn and Raun (1977) describes specific teacher characteristics as predictors of successful implementation of an innovative curriculum. six school districts within the state of Texas cooperated in a pilot center for the Science--A Process Approach. The 110 elementary school teachers were primarily volunteers participating in the inservice program. The teachers had taken from 0 to 60 hours in science.

To assess student achievement, the American

Association for the Advancement of Science (AAAS) Competency Measure was used (Commission on Science Education, 1965). The tests were individually administered with a series of questions for each exercise, designed to measure behavioral achievement of the objectives of the exercise. A percentage of the success for each class taught by a teacher was determined and the mean competency scores for each teachers' 
class was used in the analysis. Biographical data on the teachers was collected from inservice records. Using multiple linear regression analysis, the competency score was treated as the criterion to be predicted by: (a) grade taught, (b) school district, (c) years of teaching experience, and (d) hours in science courses. Teacher characteristics which appeared to predict successful teaching of an innovative curriculum were the grade level taught, and the number of years teaching experience. There was less credibility to the level being taught, due to a possible reflection of the validity of the test instruments. There was a mean correlation between the number of years teaching experience and teaching success. "A possibility is that more experienced teachers are more intuitive about children's thought processes. They are better able to judge what learning has taken place" (Bohn \& Raun, 1970, p. 159). Other studies have found teachers' age and experience related negatively to change (Berman \& McLaughlin, 1978) or found no relationship between years of teaching and teacher implementation (Ashley \& Butts, 1970). With this conflict of data on the influence of teacher experience and teacher age, it is imperative to continue investigation of these variables. This study addresses the influence of such teacher characteristics in data collection and analysis procedures. 
Teacher Beliefs

A more current way of interpreting teachers' responses to change has emerged in more recent studies. Research has moved from viewing teachers as recalcitrant to change to an approach which examines the structure and environment as context for teachers' commitment, engagement, or willingness to change (Richardson, 1990). Within all the research on teacher change there is a solid research base indicating that teachers behave according to their philosophy of teaching and out of a concern for the learning of those in their classrooms.

At a recent meeting of the American Association of Colleges of Teacher Education both Berliner (1992) and Fenstermacher (1992) addressed the tensions faced by teachers who are forced to choose between mandated programs and what is best for children. These expert educators described the dilemmas of classroom teachers who must balance their knowledge of child development, learning styles, and awareness of individual student needs with adopted curriculum and assessment materials that do not match their knowledge and awareness. Studies of beginning teachers (Shepard, 1991) provide startling data supporting the existence of such dilemmas. Furthermore, the findings demonstrate that teachers overwhelmingly make choices that are in contrast to their beliefs when under pressure of district and school mandates. The school environment which 
supports teachers, promotes collegiality, provides resources for teacher collaboration, and encourages flexibility also supports teachers in their decisions to resist programs they perceive as inappropriate (Hatch \& Freeman, 1988).

A new way of thinking about teachers' responses to change is that teachers' responses to change efforts may represent best efforts to do their job and to provide the best for students in their classroom. Failure to implement as planners hoped may signal that teachers' assessments of new practices are resulting in doubt of appropriateness and uncertainty about the outcomes for students.

Another teacher characteristic studied for influence in implementation was teacher attitude. A study by sparks (1988) was conducted with the knowledge of Doyle and Ponder's (1977) work on the practicality ethic of teacher decision making. The purpose was to study teachers' attitudes toward teaching practices presented in inservice training and the subsequent use of these practices.

Three groups of junior high teachers attended five workshops on effective teaching. Pre- to post-training observations, questionnaires, and interviews were used to assess behavior changes and attitudes. Correlational analysis indicated that teachers' post-training ratings of the importance of using the practices (congruence or philosophical acceptance) was predicative of their actual use. 
Qualitative data analysis revealed that improving teachers differed from non-improving teachers in their willingness to experiment in their classrooms and in their growth in self-efficacy. Non-improving teachers tended to defend their natural style of teaching and attempted few changes. Teacher change was not influenced by their perceptions of difficulty or ease of using the recommended practices. In other words, greater difficulty of use does not mean lower use in this study.

The significant correlations between post-training ratings of importance and observed academic interactions provide support for Doyle and Ponders' (1977) notion that practicality and congruence are determinants of change. A comparison of low and high adoption rates for teachers, with 10 case studies found the improving teachers rated the practices high on importance.

When they failed to find congruence (Doyle and Ponder, 1977) between their style and the recommended practices, these teachers were not willing to open up to making any significant changes in their teaching. (Sparks, 1988, p. 115)

Teacher Implementation Behavior

For this study we define teacher implementation behavior as behaviors related to the implementation of an Integrated Whole Language instructional approach. They include scheduling of instructional time, and use of materials as self-reported by teachers. student attitude and behavior are defined as attitudes and behaviors related 
to reading and writing as activities and preferences. Major evidence being cited as demonstration of effectiveness in Whole Language research is teachers' enthusiasm for children's responses to literature (Coley, 1990; Prater \& Terry, 1985). In Coley's study of reading supervisors, teachers observed children choosing books over toys and better handling of books. This survey was conducted by calling every county in the state of Maryland, for a state-wide cross section of reading supervisors. They asked the question "What is the good news and the bad news about Whole Language from their perspective?" Coley notes that the teachers' enthusiasm for Whole Language paralleled and grew with the students' enthusiasm. This supports Doyle and Ponders' (1977) notion of "congruence" and Mahlios and Bromley's (1984) bi-directional model of classroom interaction in which both the teacher and students exert influences on one another. The study described here seeks a similar relationship between teachers' implementation behaviors and their students' attitudes toward reading and writing. A relationship between student reading and writing behaviors and teacher behaviors is also sought.

Ashley and Butts (1970) focus on the effect of inservice on the teaching act in their assessment of an inservice education program on teaching behavior. Their study involves: 
1. Identification of strategies of teaching which are an integral part of a curriculum sequence that emphasizes cognitive behavioral outcomes in students,

2. Designing of a Classroom Observation Rating Form (CORF) to sample these strategies as they are employed by teachers in using lessons from Science--A Process Approach,

3. Evaluation of the impact of an inservice program on teacher use of these strategies,

4. Analysis of teacher attitudes and how they relate to modification in teacher behavior.

5. Analysis of the relationship between years of teaching experience and teacher grade level taught and modification in teacher behavior.

Twenty-three teachers, representing grade levels one through six, were enrolled in the inservice education program. The inservice consisted of 11 meetings designed to inform the teachers of the curriculum sequence. The meetings also offered discussion, demonstrations and preparation of lessons.

Direct observation was used to ascertain teacher behavior. The study assumes that teacher behavior represented the impact of inservice education and the significance of attitudinal change. The CORF was used to sample the classroom behavior of teachers. A semantic differential was used to ascertain the attitudes of the teachers toward the curriculum sequence and inservice. 
The inservice education program was considered a constant and the level of use of strategies was considered a variable. The findings show that during the course of the school year there was a decrease in behavior consistent with the curriculum. The teachers seemed to reach a plateau for using the strategies at the time of the first science observation. The results relevant to this study are that the for the duration of the inservice there was an increase in positive behavior strategies. It can be said that inservice has an affect on teachers implementation.

There are conflicting results in determining teachers implementation behaviors. Harste (1977) finds that teachers planning decisions remain consistent theoretically and that they match and predict teachers' in class behavior. Schmidt et al. (1983) finds inconsistencies in use, teachers reported theoretical base was not evident in their implementation behavior.

As noted earlier in the review of the literature, significant correlations between post training ratings of importance and observed academic interactions (Sparks, 1988) provide support for Doyle and Ponders' (1977) notions of practicality and congruence. It is established that the factors affecting teachers during change vacillate during the period of implementation. This lack of agreement and variance of perspective direct this and future studies of teacher implementation to investigate with a wide lens. 
TEACHER BEHAVIORS AND STUDENT BEHAVIORS

Mahlios and Bromley (1984) find student influence patterns are more closely related to higher levels of achievement and positive student attitudes. Their study was conducted to examine student initiated and teacher initiated influence patterns that make up aspects of bi-directionality. The study identifies ways in which these patterns relate to student learning and attitudes. The study subjects included 21 fifth grade students and their teacher. Thirty-six social studies lessons, representing a unit, were videotaped over a 10 week period. classroom interaction was assessed with an adaption of the Teacher Child Dyadic Interaction instrument (Brophy \& Good, 1969). Learning was assessed with 30 question multiple choice tests administered during and following the study. Attitudes toward the teacher and lessons were assessed with "Pupil Perceptions of a class Period" and "Post-class Reactions" (Fox, Luszki, \& Schmuck, 1966). Their study, along with others, confirms that students affect the behavior of teachers (Fiedler, 1975; Klein, 1971; Noble \& Nolan, 1976). student behavior demonstrated in response to teacher behavior has recently been recognized as a powerful modifier and controller of teacher behavior. It results in specific changes in classroom events and instruction. In a study by Bedrosian (1983) teacher/student interactions were analyzed through verbal and non-verbal 
analysis to investigate the social/emotional dimension of teacher/student interactions. Bedrosian notes that traditional methods of assessment fail to recognize this dimension. The purpose of the study was to:

1. describe the social emotional environments of high and low ability reading groups (highlighting student initiated events, question/responses, evaluation events);

2. compare observer and student perceptions of differential teacher treatment;

3. determine the relationship between the social emotional environment and instructional effectiveness. Beginning groups in four first grade classrooms were videotaped. A social-emotional coding manual was used to code transcripts of teacher behaviors of informality, trust, warmth, and support as reflected in the teacher student interactions. Data analysis was directed to investigate the differences between the high and low ability groups. The findings show that the social emotional environment is more favorable in high ability reading groups, although the extent and manner of differential treatment varies with teachers. Observer and student perceptions of differential teacher treatment are in agreement for two of the four classrooms. Instructional effectiveness was scored higher in reading groups with the more favorable social emotional environments. 
In terms of identifying student behavior toward literature, Hickman (1979) uses an ethnographic approach to identify a broad range of response behaviors, compare age level differences and discover patterns related to classroom contexts. He finds that children express responses to literature in a variety of ways.

The investigator acted as a full-time participant observer in an open space, informal, elementary classroom. Three groups totaling 90 children and representing $\mathrm{k}-5$ th grade levels were studied during the first four months of the school year. Each group was observed intensively for 20 days. Evidence was collected in the form of descriptive notes and anecdotal records and tapes; discussions and interviews with the children and photos of the children's work.

The primary focus was on teachers' own literature programs. The investigator systematically collected responses to one picture book to facilitate comparison across grade levels.

Findings indicate that children express responses to literature in a variety of ways; many of them differ from conventional oral or written response statements. Non-verbal behaviors such as informal sharing and browsing were observed. Free comments were the prevalent spontaneous responses. Other responses include imitating or demonstrating meanings in drama, making various products 
(pictures, games, collections) based on literature, and writing with a story as a model. Across grade levels, students were concerned with making sense of a story. The teachers influenced the responses by providing many books and allowing for maximum accessibility. They read aloud everyday, discussed books frequently, furnished materials for book extension activities, and provided for group sharing and display of literature related projects. Response to literature was seen as long-term and cumulative. It is established that teacher and student behaviors influence each other. Researchers have begun to look for alternative ways of measuring and identifying these behaviors. There is a need for future research in this area, especially for the assessment of non-conventional behaviors as noted by Hickman (1979). This study addresses the need by asking both teachers and students to describe their behaviors related to language arts teaching and learning.

TEACHER BEHAVIORS AND STUDENT ATTITUDES

The research explores the relationship between teacher levels of implementation of an Integrated Whole Language approach and the attitudes of students toward reading and writing. The research design addresses student attitudes because research has demonstrated relationships between 
student attitude and achievement. Studies documenting the importance of student attitude are reviewed in this section. Fein and Solomon (1990) study the relationship between student reading achievement and student reading attitudes. Achievement was measured by standardized test scores and attitude was measured by students' and teachers' responses to a set of 10 attitudinal items from the National Assessment of Educational Progress (NAEP). Both tests were administered to 131 fifth graders; appropriate data was available for 114 students. The Kruskal-wallis analysis of variance by ranks procedure was used to determine relations among students' opinions of their reading ability and standardized test performance. Students' and teachers' opinions of students' reading achievement were also | compared.

Findings indicate that teachers' opinions were consistent with students' standardized test scores and that teachers labeled twice the number of students as good readers as students themselves. Other studies have shown a positive relationship between student attitude and reading achievement (Navin \& Bates, 1986) and that student performance on attitude scales predicted achievement (Richards \& Bear, 1987).

Cappleman (1983) finds that the beliefs and instructional emphasis of teachers affected the reading strategies of students, but show no effect on attitudes. 
Kelley and chin (1967) find that attitudes toward school and reading are a function of intelligence and reading readiness when reported by teachers. When reported by students they find attitudes are a function of the type of instruction used. Neale, Gill, and Tismer (1970) report that children possess a characteristic attitude toward individual subjects and these attitudes determine the studying behavior and learning in each subject. Consideration is given to the possible influence of subject matter and instructional approach on students' attitudes in the study described here. There is a need for increased research efforts to assess teacher behavior and its relationship to student attitude and behavior in the context of individual subjects, areas for curriculum, type of instruction, teachers' theoretical base and actual use of instruction. All of these factors are addressed in this study of the implementation of the Integrated Whole Language approach.

\section{SUMMARY}

This chapter provides a review of the literature related to and in support of this study of an implementation of an Integrated Whole Language approach as a change process. In summarizing the literature it is established that the change process needs to be considered in terms of factors affecting change. Within the literature is a call for more descriptive studies of implementation to determine 
influencing factors. Even though student achievement is the impetus for change, it is not a valid assessment or outcome measure of implementation.

The research also points to the need for teacher input. It is established that teachers have strong philosophical beliefs about their profession and adhere to their theoretical bases. As the primary implementors of innovations, they need to be viewed as valid resources in curricular decisions. The influence of teachers in successful implementations is further supported by a changing role of the principal. As a facilitator of change, a principal is responsible for creating an environment conducive to change. That environment includes adequate inservice and materials that are supplied prior to implementation; and that throughout the process there is open communication. This study considers teachers, the administrator's role, and environmental factors in a description of the Implementation of an Integrated Whole Language approach.

The research also highlights a need for future studies designed less with traditional research methods in assessment of implementations and in exploration of relationships between teacher behavior and student attitude and behavior. This study employs a blend of quantitative and qualitative methodology with the intent of describing implementation rather than assessing the process. This 
study extends the research base, probing the relationships between teacher and student behaviors by viewing it as part of a larger picture. This study has potential to make valuable contributions to the major areas of research cited in this chapter. 
CHAPTER III

STUDY METHODOLOGY

INTRODUCTION

\section{Study Purpose}

The purpose of this study is to describe the implementation of a major curriculum change (at the fifth grade level) in two different school district settings; an urban district and a suburban one. The major curriculum change examined is the shift from a traditional reading and language arts program to an Integrated whole Language program. The implementation of this change is examined on the basis of self-reports by teachers, students, and administrators. The implementation is described in the context of organizational factors in schools that have typically influenced change: school district demographics, decision making-process, administrative support, inservice training, the principal's leadership role, and resources available. Additionally, the study investigates the relationship between teachers self-reported implementation behaviors and student self-reported attitudes and behaviors. 


\section{Chapter contents}

This chapter presents the methodology for this study with descriptions of the sample and instrumentation. A sequence is described for the pilot study, the research study, and for data analysis. Data analysis procedures are presented in relation to each of the research questions. A blend of qualitative and quantitative research methodologies are employed to describe the implementation of a new instructional approach as a change process in the context of district, school, teacher characteristics and factors with potential to influence change.

\section{Research Approach}

This study investigates the implementation of an Integrated whole Language approach at the fifth grade level. The implementation is viewed as a change process for the purpose of the study. The implementation is examined and described in the context of school organizational factors which have been shown to influence change. Within this is a recognition that change is highly personal, therefore it is imperative to not only empirically measure the change process, but to extensively describe the environment and the people which are affected by the change. Therefore, this study employs a blending of qualitative and quantitative research methods in an attempt to describe all the variables that play a role in the development of change. 
The study involves two school districts; one urban and one suburban. Extensive descriptive data were collected about the school districts, the schools, the administrators and the teachers. Teacher and administrator interviews were conducted to gather description of the organizational factors that play a role in the change process. Teacher and student questionnaires were administered to investigate teacher self-reported implementation behaviors and student self-reported attitudes and behaviors. Teachers were asked to identify the type of instructional methodology and materials used, number of inservices attended, and amount of time spent teaching language arts. Teacher questionnaires were compared with an "ideal profile" of an Integrated Whole Ianguage teacher and scored according to presence of Integrated Whole Language use. The teacher scores were then used to describe differences between teachers, schools, and districts. students were asked to identify the number of books read, amount of time spent reading, and their preference for reading over other activities. Differences in teachers' scores were used to explain differences in students' responses to the questionnaire items.

\section{Support for Proposed Approach}

This study focuses only on specific descriptions of the implementation process. This decision responds to the lack of descriptive studies in the research on curricular 
and instructional change implementations. This decision is further reflected in the lack of evaluation data, specifically student scores, for two reasons: the change process takes time (Hall et al., 1973) and collection of such evidence would be premature during the first year of implementation; and current assessment approaches in language arts are not well matched to/content and process of the Integrated Whole Language instructional approach (Huebsch, 1991; Sanacore, 1990).

A descriptive approach for this study allows the process of change to be viewed in the environment in which it occurs and understood in the context of demographics, conditions, procedures, and assessment of attitudes and opinions (Gay, 1987). There is a need to understand the people involved in the change; to provide voice for their beliefs, emotions, personal philosophies and interactions with others in the environment: (Ary, Jacobs, \& Razavieh, 1985; Nistler \& Shepperson, 1990). "This mode of research brings the study of human beings as human beings to center stage" (Rist, 1982, p. x). Teachers are human and therefore this study includes their personal interpretations and experiences in the context of the situational factors which affect them as individuals. Collection of demographic data also attends to the individual qualities of teachers.

Contextual data were collected from historical records and interviews with teachers, school, and district staff. 
The interview questions were developed to generate more specific information regarding the implementation as a change process and to reflect the organizational factors known to influence change. Other sources of data are teacher self-reported implementation behaviors (questionnaires) and student self-reported attitudes and behaviors (questionnaires).

These two instruments, the questionnaire and the interview, can supply extensive data concerning facts, feelings, and intentions when used properly (Ary, Jacobs, \& Razavieh, 1985). The problems associated with them arise from misuse, such as not checking the validity (if they are measuring what they say they do) and the reliability (consistency of results). Gay (1987) recommends that instruments be pre-tested to check for validity and reliability. By doing so, instruments are refined and qualified. A pilot study was conducted to clarify the questionnaire items and rehearse questionnaire procedures for this study. The interview protocol was also tested for clarity and ease of eliciting responses. Measures of reliability and validity were included in the data analysis procedures for the questionnaire and are described in the Data Analysis Procedures.

The decision to utilize these two self-report procedures along with gathering contextual data was based on a twofold rationale. The interview can produce in-depth 
data not possible with a questionnaire, but is feasible with only a small sample. The questionnaire on the other hand allows for extensive information to be collected from a much larger sample (Gay, 1987). The data generated by these procedures is analyzed in response to each of the research questions.

A combination of qualitative and quantitative methods was chosen in order to comprehensively describe the implementation process. The qualitative data in the form of descriptions of district, schools and teachers support and explain differences or lack of differences in the quantitative data. The teacher self-report behaviors are interpreted in the context of qualitative descriptions.

\section{Research Questions}

This study is guided by a set of assumptions derived from a change model developed for study of curricular change by researchers at the University of Texas in Austin (Hall, Wallace, \& Dossett, 1973). The Concerns-Based Adoption Model ( $C B A M$ ) acknowledges the organizational and social influences, but regards the teacher as the central focus in change efforts. The CBAM views change as a process experienced by individuals. This theory is reflected in their assumptions about change. They include:

1. Change is accomplished by individuals, not institutions.

2. The change process takes time. 
3. Change is highly personal and influenced by experiences, emotions, expertise, and skills.

4. Change is developmental growth in both feelings and skills in using a new program.

The research questions guiding this descriptive study are based on those assumptions about change. To describe the implementation of an Integrated Whole Language instructional approach, the following questions are posed:

1. How do teachers and administrators describe the change related to implementation of the Integrated Whole Language approach? Are there individual and group differences in perceptions of the change?

2. How do teachers describe their language arts instruction during the first year of implementation of an Integrated Whole Language instructional approach?

3. Are there differences between teachers, between schools, and between districts, as measured by teacher implementation scores?

4. Is there a relationship between teacher implementation scores and teacher characteristics (demographics)?

5. Is there a relationship between teachers' implementation scores and contextual factors in the education settings (district differences)?

6. How do students describe their attitudes and behaviors related to reading and writing during the first 
year of implementation of an Integrated Whole Language instructional approach?

7. Is there a relationship between student attitudes and behaviors and their teacher's scored implementation of the Integrated Whole Language approach?

This study extends understanding of the process of change in schools, specifically the change involved in implementing new approaches to instruction. These questions will guide the data analysis in describing implementation of an Integrated Whole Language approach as a change process.

\section{SAMPLE}

The sample consists of 27 fifth grade teachers and 651 students from two public school districts in oregon. The two districts are a large (over 50,000 students) urban district and a medium (under 10,000) suburban district. A random sample of five elementary schools from each district were selected to participate in this study. Within the random sample of schools, participation was voluntary. One school in the suburban district elected not to be a part of the study. The urban district consisted of 16 teachers and 412 students. The suburban district consisted of 11 teachers and 239 students. The schools in the urban district are located fairly close together in neighborhood settings. The suburban district's schools have more distance between them as typically observed in a rural 
environment. The remainder of the sample descriptions are in the contextual data as results in Chapter IV of this study. The descriptions are presented in the form of mini cases of the two school districts to guide interpretation of school and teacher data.

\section{DATA COLLECTION PROCEDURES}

\section{Pilot study}

The primary objective of the pilot study was the testing of the research instruments. The pilot study of the teacher and student questionnaires was conducted by the investigator one month prior to the administering of the questionnaires. The sample included two fifth grade teachers and their students in one school. The pilot study for the interviews was conducted one week prior to the scheduled interviews. The sample included the same two fifth grade teachers and the school principal. Both instruments were revised to ensure clarity in eliciting responses to the questions.

\section{Contextual Data Collection}

The contextual data was gathered by a research assistant through telephone and in person interviews. Information was gathered by interviewing district level administrators, school principals, and teachers. Information was also gathered in the form of documents, publications, records, and other related literature. Basic 
demographic data on the districts was included in the contextual data collection.

Artifacts in the form of printed information such as readings, brochures and announcements comprise additional data. The information is used as descriptive evidence of the implementation process. The collection of such artifacts is based on the following criteria: district distribution, principal use, and teacher use.

\section{Interviews}

Interviews were conducted by the investigator and a research assistant in both school districts. The majority of teachers participating in the first data collection were interviewed. A limited number of principals from the nine schools and a limited number of administrators from the two districts were interviewed. The interviews were conducted with all participants who were available and agreed to participate.

\section{Demographics}

Three categories of demographics were included in the data collection. The district demographics include number of schools, amount of personnel, and enrollments. Teacher demographics such as number of years teaching, age, gender, and education are supplied from questions 15 through 19 on the teacher questionnaire. Student demographics such as age and gender are supplied from questions 11 and 12 on the 
student questionnaire. Question number 19 on the teacher questionnaire will supply the student economic status.

Teacher Questionnaires

The teacher questionnaire was developed by the investigator. The questionnaires were administered in person to the urban district and by mail to the suburban district. They were completed in the spring of 1988 , nine months after the formal implementation of the Integrated Whole Language approach had begun.

\section{Student Questionnaires}

The student questionnaire was developed by the investigator. The questionnaires were completed during the same time period as the teacher questionnaires. This procedure was followed in the participating schools in both districts. The investigator administered and collected the questionnaires for the urban district. The questionnaires were administered by teachers in the suburban district.

\section{DATA ANALYSIS PROCEDURES}

The data were analyzed to describe the implementation of a new instructional approach as a change process in the context of district, school, teacher characteristics and factors with potential to influence change. The contextual data were organized and presented in mini cases of the two school districts. Research literature describing factors 
which support teacher change guides the analysis of the contextual descriptions. The research questions serve as a guide for the data analysis procedures. A blend of qualitative and quantitative methods will be employed.

In response to Question 1, "How do teachers and administrators describe the change related to implementation of the Integrated Whole Language approach?" and "Are there individual and group differences in the perceptions of change?" The data responding to these questions is qualitative. Descriptive analysis documents the participants' perceptions of the change and the differences between individuals and groups (schools, districts).

In response to Question 2, "How do teachers describe their language arts instruction during the first year of implementation of an Integrated Whole Language instructional approach?," teachers' responses to the questionnaire is be analyzed descriptively (see Appendix B).

Before responding to Question 3, individual teachers' responses to the questionnaire were be scored by comparison to the "ideal profile" of an Integrated Whole Language teacher. The "ideal profile" was generated by experts in the field of language arts to reflect a whole Language oriented approach. This comparison yielded an implementation score with which to describe responses to Question 3, "Are there differences between teachers, between schools, and between districts in implementation scores?" 
From there, a frequency distribution displayed the differences between teachers and schools. To establish the presence or absence of significant differences between the two districts, a $\underline{t}$ test procedure was used.

The procedures for establishing an "ideal profile" served as a validity check for the teacher questionnaire. When the experts described a question not appropriate, it was eliminated from the data base. When the experts could not agree about the best response for a "Whole Language teacher," that item was not included in the data base. These procedures for establishing the "Ideal Profile" also included a test/retest check for reliability. Due to a very small sample, three experts, no statistical analysis was done.

In response to Question 4, "Is there a relationship between teacher implementation scores and teacher characteristics/teacher demographics?" the analysis will consist of chi-square and $t$ test procedures depending on the scale of measurement for the demographic data.

In response to Question 5, "Is there a relationship between teachers' implementation scores and contextual factors in the educational settings (district differences)?" the mini-cases of the districts provides a context for descriptive analysis of teacher implementation scores for school and district differences. 
In response to Question 6, "How do students describe their attitudes and behaviors during the first year of implementation?" a descriptive analysis of students' responses to the questionnaire items was conducted.

In response to Question 7, "Is there a relationship between students' attitudes and behaviors and their teachers' scored implementation of an Integrated Whole Language instructional approach?" the analysis was directed to explaining the differences in students' responses to the questionnaire items by differences in teacher's implementation scores. The analysis employs chi-square and Pearson Product Moment procedures.

Each set of findings is presented in relation to the research question to which the results are directed. Qualitative research methodology is employed through content analysis of the data sources (interviews and questionnaires) (Merriam, 1988; Miles \& Huberman, 1984). Questions 1, 2, 5, and 6 are analyzed descriptively for categories of differences and similarities for the participant groups, and emerging dominant themes. Responses are organized topically. Analysis required repeated reading and sorting into conceptual categories. Triangulation emerged through repeated examination of the data sources for consistencies and themes. 
SUMMARY

"Given the complexity of the phenomenon of implementation, the factors that could plausibly influence it are potentially enormous in number" (Fullan \& Pomfret, 1977, p. 367). This study conceptualizes implementation as a change process in an effort to reflect the complexity. Acknowledging what is known about change allows this study guidance in describing the implementation of an Integrated Whole Language approach. A framework based on assumptions about change directed development of the research questions and guided the data analysis (Hall et al., 1973). The blend of qualitative and quantitative research methodologies employed in this study allows for "plausible influences" to surface. 


\section{CHAPTER IV}

\section{FINDINGS}

INTRODUCTION

\section{Study Purpose}

The purpose of this study is to describe the implementation of a major curriculum change (at the fifth grade level) in two different school district settings; an urban district and a suburban one. The major curriculum change examined was the shift from traditional reading and language arts instruction to an Integrated Whole Language instructional approach. In this chapter, the implementation of this change is examined using self-reports by teachers, students, and administrators and is described in the context of organizational factors in schools that have typically influenced change. These include school district demographics, decision making process, administrative support, inservice training, the principal's leadership role, and resources available. Additionally, this study investigates the relationship between teacher self-reported implementation behaviors and student self-reported attitudes and behaviors related to reading and writing. 
Chapter Contents and Format

This chapter presents the findings of this study. The research questions are reviewed accompanied by descriptions of methodology and findings. For each question, results are presented with examples and summaries. The format varies for each analysis.

FINDINGS FOR QUESTION ONE

Research Question and Analysis Procedures

"How do teachers and administrators describe the change related to implementation of the Integrated whole Language approach?" As the interview responses to this question were described, the analysis responded to additional questions: "Are there individual and group differences in the perceptions of change?" (see Appendix A). The data were qualitative. Descriptive analysis procedures were followed to determine participants' perceptions of the change and subsequent rereadings were conducted to identify the presence or absence of differences between individuals and groups (schools, districts). The procedures involved looking for common language among administrators' and teachers' descriptions and differences in descriptions among administrators' and teachers' responses. The descriptions were then grouped by school and district to look for commonalty and differences within schools and between districts. 
Common Descriptions of the

Change

To determine the "common descriptions of change," the entire sample, teachers and administrators, was considered. The most common description by teachers and administrators of the change related to implementation of an Integrated Whole Language approach included words and phrases referring to the approach itself, such as "already doing it," "already been using it," and "it validated what teachers were already doing." These responses referred to the actual instructional approach and indicated that the change was not a change in practice for many teachers. In addition, positive support and usefulness, again referring to the approach, were expressed in phrases such as, "freeing up, release of restrictions and limiting factors" and "license to continue," and were also frequent responses. Words and phrases directed more to the actual transition or change were, "slow," "gradual," "not an effective transition," and "it required staff development." These expressions referred specially to the change process and were not frequently found in responses to question one when the entire sample of response was analyzed.

The majority of the administrators' and teachers' descriptions of the implementation indicated that the Integrated whole Language approach was not new to many teachers and the formal implementation allowed and supported those teachers to openly and comfortably implement the 
instructional approach. Although there was generally positive response to the instructional approach, some descriptions describing the change process were less enthusiastic. Although a majority of teachers reported "already using it," it appears that those teachers who were unfamiliar with the approach were struggling in the change process and/or the formal transition which accompanies an implementation.

\section{Differences in Descriptions}

Between Teachers and Administrators

Beyond the common language described in the previous section, individual teacher's descriptions differed from individual administrator's descriptions. Most administrators referred to teacher responses rather than self-responses in their descriptions and used phrases such as "mixed feelings," "wide range of views, some responded, some struggled, some were skeptical, willing or resistant," and "change was different for each individual." Their descriptions acknowledged the diversity of teacher responses. This theme was also evident among teacher responses but the more prominent theme was that teachers were "already using it." It appears that administrators perceived more diversity among teachers than teachers acknowledged for themselves.

A significant difference between teachers' and administrators' responses was the presence of language 
describing the Integrated Whole Language approach in the teacher responses and the absence of such language in administrator responses. The majority of teachers responded with descriptions such as these:

"removed pressure of using basal text,"

"able to use literature that was interesting to the students, "

"less focused on detailed skills, more reading and writing and integration, and whole class activities."

Actual practice and classroom use is evident in these descriptions from teacher responses. It is interesting to note that only one administrator responded with language similar to these teacher descriptions. Most teacher descriptions reflect understanding and use of the Whole Language instructional approach, however the responses of most administrators indicated a lack of familiarity with the instructional procedures and philosophy as indicated by a lack of whole Language practices in their descriptions.

\section{Differences within the Teacher}

\section{Sample}

Teacher descriptions displayed thematic diversity within the teacher sample. The most prominent theme described feelings of support or affirmation of current practices as evidenced in these common teacher responses:

Teacher A: "freeing up, release of restrictions and limiting factors, a relief." 
Teacher B: "Had already been using it. Gave license to be able to continue."

Teacher C: "Already doing Integrated Whole Language approach. It was not new to most of the people in the building."

Teacher D: "The change to Whole Language removed the pressure of using the basal text. Able to bring in other literature that was of interest to the students, which increased the student's interest in reading."

These descriptions reflect both the teachers' beliefs in the Integrated Whole Language approach and a dissatisfaction with the limitations they perceived with traditional methods. The teachers were at ease with the transition because it represented little change to them. The change held support for their beliefs and practices.

Two other themes emerged that were less dominant but that reflected the diversity within the teacher descriptions. The first was one of excitement and enthusiasm for the new approach. It is reflected in these descriptions:

Teacher A: "Excited about the change. Yes, this is the right way to teach kids."

Teacher B: "The change was extremely positive. It made my teaching more effective." 
Teacher c: "The change was positive, but a lot of work. It was exciting and invigorating and continues to be so."

These teachers did not specifically describe the approach as already part of their teaching. There was indication in their language that it represented a change in approach and they perceived the change positively.

The second theme was one of insecurity and reference to the need for time and training. Examples of this theme are:

Teacher A: "Difficult. Took awhile to understand what they wanted with whole Language. It doesn't use structure, but I do."

Teacher B: "Liked the idea, but there wasn't quite enough information or training to be properly prepared. Teacher C: "Slow, frustrating sometimes, but for the good."

These responses comprise a contrast to the first and second themes of response in the perceptions of change. These responses required additional analysis in that they contained subthemes. One subtheme in their descriptions partially reflects hesitation and dissatisfaction with the change process. The second subtheme is a response to the instructional approach. Specifically, there was support and positive perceptions of the approach in their language (teachers $A$ and $B$ ). However, teacher $C$ was one of three 
teachers in the total sample who expressed dislike for or lack of acceptance of the Integrated whole Language approach.

Differences within the Administration Sample

Administrator responses were analyzed for differences among the sample of administrators. There were no significant differences found between the response themes of district level administrators and the responses of principals. However, when administrators were viewed as a group there were diverse themes in their responses. The first, a theme of validation, similar to that found in the teachers' descriptions, was evident through phrasing such as these:

Administrator $A$ : "The change was dramatic. It had a freeing effect on teachers, allowing them to continue to do things they had already been doing."

Administrator $B$ : "Whole Language is a new way of looking at children's literature. The change validated what teachers were doing. Change was different depending on where the teacher was coming from."

Administrator c: "We were one year ahead of the district. The teachers had been experimenting and were studying the process so the transition was easy because of the work already done." 
These descriptions showed that some of the administrators were knowledgeable that teachers were already using the approach and that they were sensitive to the individual differences in response to the change. only two components of Integrated Whole Language, use of children's literature and wholistic view, appeared in the administrators' responses.

A second theme found in administrators' responses was one of inadequacy and ineffectiveness as reflected in these descriptions:

Administrator A: "The change was a change in philosophy. It was not a very effective transition. The staff had to drop what they were doing. Now they are backtracking. It was awkward the way it was gone into." Administrator B: "Slow. People have a difficult time changing. Needed staff development."

These descriptions reflected an inadequate preparation before the transition. There was a similar reference to the dissatisfaction and need for time and training found in the second theme of teachers' responses.

A third theme, that of recognition of individual differences and a continuum of views among staff concerning the change, was found in the administrators' responses. Some examples were: 
Administrator A: "Wide range of views about it. Some were able to respond. Some were already doing it. Some struggled."

Administrator B: "Mixed feelings. Immense immersion in process-inservicing, workshops, mini workshops. A lot who wanted to try it and others who wanted to really know it before doing it, so the process has taken several years. Some teachers aren't convinced as to the value."

Administrator c: "Slow. Some were excited. Some had already tried whole Language. Some were skeptical. Some were willing to try it. Some were resistant, however they liked the materials."

Among the administrators there was a recognition and allowance for individual responses to the change. There was also evidence in these responses that administrators were aware that not all teachers were convinced that Integrated Whole Language was the best instructional approach. They acknowledged some of the feelings expressed in the third theme of teachers' responses.

\section{Differences Between Districts}

The responses within both districts were varied. However, a more common theme in the responses from the suburban district was that the change was slow. The descriptions included phrases such as: "Slow," "frustrating," "the process has taken several years." These phrases were included in $50 \%$ of the responses of teachers 
and administrators from the suburban district. The urban district responses included similar phrases but they only accounted for $25 \%$ of the descriptions. It appears that teachers in the suburban district experienced or perceived more difficulty in implementing the change than teachers in the urban district. The differences in descriptions also indicated that more teachers in the urban district were already practicing the Integrated Whole Language approach before any formal district implementation.

\section{Differences Within Individual}

Schools

Similarity of responses within schools, that is, congruence between teachers' and administrators' descriptions, was found in only one school in each district (1 and 9). Otherwise, significant contrasts were found between teachers' and principals' responses, and among teachers' responses when viewed within the context of individual schools. Examples of such contrast from two schools illustrate the differences which existed within most schools in both districts when descriptions were analyzed. School 6.

Principal: "Dramatic, freeing effect on teachers, they continued to do what they had already been doing."

Teacher A: "Confusing."

Teacher B: "Main change was that district would provide literature instead of basal text." 
Teacher c: "Yes, this is the right way to teach kids!"

Teacher D: "The change to Whole Language removed the pressure of using basal text. I was able to bring in other literature that was of interest to the students."

within this school was a diversity of responses which ranged from enthusiastic support to confusion and from support of teachers' practices to seeing the approach as merely provision of literature.

School 7.

Principal: "Required staff development, uncomfortable, required study, staff meetings, parent training."

Teacher A: "Positive, a lot of work, exciting, invigorating, continues to do so."

Teacher B: "Less focus on detailed skills, more reading, reading, writing and integration, whole class activities."

Within this school there was an admission that the change process takes effort and planning. The responses ranged from uncomfortable to invigorating, and from a rejuvenation of teaching practices to merely identifying the procedure change.

These descriptions illustrate very little congruence between the principal's and the teacher's responses to the change. They portray contrasting perceptions and affect, a 
range of understanding, and presence and/or absence of support within a single school context.

Some significant differences were found within

teachers' responses in individual schools. An example follows.

School 2.

Teacher A: "Already doing it, not new to most people. Teachers were left on their own to implement as they felt comfortable."

Teacher B: "Wasn't enough information or training to be prepared. Too fast. The district jumps on new ideas, but there is not enough preparation to make it a success." Teacher c: "putting more choices in the hands of kids, more writing and editing."

Within this school the responses encompass validation of practices from the change, lack of confidence because of the change occurring too quickly and without preparation, to an acknowledgement of the differences in the instructional procedures. These descriptions support earlier findings, that of diversity in teachers' responses. Additionally, the findings viewed in the context of individual schools indicate that the same diversity exists in most schools. The descriptions illustrate a range of perceptions which encompasses enthusiasm, understanding, dissatisfaction, discomfort, and presence and/or absence of support within a single school context. 
FINDINGS FOR QUESTION TWO

Research Question and Analysis

procedures

"How do teachers describe their language arts instruction during the first year of implementation of an Integrated Whole Language instructional approach?" To respond to this question, this study analyzed the teachers' responses to the questionnaire using descriptive analysis (see Appendix B). The responses were analyzed for similarities and differences in descriptions among the teacher sample, within the schools and between the districts.

Common Descriptions of Language Arts Instruction

The most common wording teachers used to describe their language arts instruction was "Whole Language." There were a few responses specifying "Integrated Whole Language." other descriptions included "novels," "oral reading," and "writing as process." Most teachers described the approach with appropriate language, with a few descriptions identifying the methods involved.

\section{Differences Between Districts}

There was a considerable difference in descriptions between the two districts. Every teacher in the urban district mentioned "Whole Language" in describing their approach, with one exception. One teacher did not use 
"Whole Language" in his description but replied with "Success programs--Cooperative learning and others." As a group the urban district teachers used only vocabulary depicting the Whole Language approach or an Integrated Whole Language approach. Some examples are:

Teacher A: "Whole Language with integration of reading, language, speaking, writing, and spelling into other areas of curriculum. I use novels in lieu of basal readers."

Teacher B: "Whole Language integrated approach using novels and the writing process."

Teacher c: "Whole Language-class novels, sustained silent reading, reading conferences, daily oral language, writing workshop."

These descriptions reflect a working knowledge of the approach and the materials involved.

In the suburban district there was more diversity within the teachers' descriptions. Only $35 \%$ used "Whole Language" in their descriptions, however the descriptions did reflect a Whole Language approach as evidenced in these examples:

Teacher A: "Integrated theme approach using trade books, writing as a process, library books, etc." Teacher B: "I use my reading program as a basis for my language arts through the use of novels and tradebooks." 
Teacher c: "Whole Language, emphasizing literature around social studies and science themes."

Within these descriptions is an understanding of the methods involved in the approach and the integration of the language arts program in other curriculum areas.

\section{Differences Within Individual}

\section{Schools}

There was significant diversity within the teachers' descriptions in one school in the suburban district. The teacher descriptions are as follows:

Teacher A: "Daily oral language, traditional, whole language at times."

Teacher B: "A combination of Integrated Whole Language and traditional skill-based."

Teacher C: "Whole Language."

Two of the teachers descriptions in this school are significant in that they are the only responses in the sample that used "traditional" in the description of their language arts approach. The research has shown that principal support plays a role in teacher implementation. For the purpose of this study, the response to the interview question one from the principal in this particular school follows (see Appendix A).

Principal: "Wide range of views about it. Some were able to respond. Some were already doing it. Some struggled." 
The principal's response reflects one of the themes prevalent among the administrators, a recognition of individual differences.

FINDINGS FOR QUESTION THREE

\section{Research Question and Analysis}

Procedures

"Are there differences between teachers, between schools, and between districts in level of implementation?" The analysis of data responding to this question required triangulation of quantitative and qualitative data and procedures. Analysis procedures directed that individual teachers' responses to the questionnaire would be scored using the "ideal profile" of an Integrated Whole Language teacher. The "ideal profile" was generated by experts in the field of language arts to reflect the instructional approaches, instruction materials, scheduling considerations, and thinking about teaching and learning of a Whole Language teacher. The process of developing the "ideal profile" served as a validity check as described in Chapter Three. Only those items agreed upon by experts were retained for the analysis. A scoring system with a range of 0 to 15 points was developed through analysis of the responses of the language arts experts. This scoring system accommodated an appropriate range of responses to several of the questionnaire items rather than narrowing the "correct response" to a single option. For example, in response to 
question 14 on the teacher questionnaire, a Whole Language teacher could select all four methods of instruction because the approach is such an eclectic one. This scoring procedure achieved a consistency with the Whole Language philosophy and instructional approach.

Once the scoring system and "ideal profile" were developed, individual teachers' responses were scored. A frequency distribution was developed to look for differences between teachers. This procedure revealed the presence of outlyers, that is a set of teacher scores at very high levels and a set of teacher scores at very low levels. These two groups were then examined using qualitative data to verify and expand understanding of differences between teachers.

\section{Differences Between Teachers}

The majority of teachers' scores indicated implementation of the Integrated Whole Language approach. Most scores are in the mid to high level, with a few outlyers. The outlyers are scores reaching outside the majority of implementation scores and they represent a visible difference in teacher scores. It was decided to descriptively analyze the four lowest teacher scores and the eight highest teacher scores to better describe the differences. This process analyzed the teachers' interview responses in relation to their implementation scores. 
Figure 1 shows the frequency distribution for the teacher sample.

Number of

Teachers

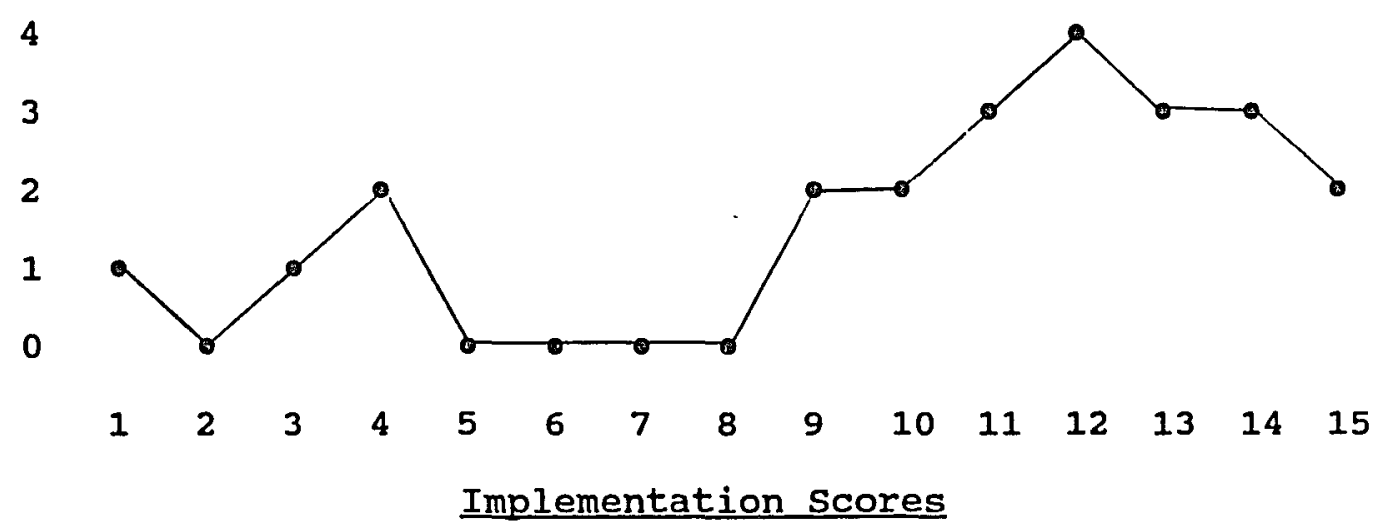

Figure 1. Frequency distribution for teacher sample.

Interview data were analyzed in relation to the eight highest teacher scores and the four lowest teacher scores. There were a relationship within the two groups. Common descriptions of the change for teachers with implementation scores of 14 and 15 included phrases such as, "already changed," "freeing up, release of restrictions," and "removed pressure of using basal." These descriptions reflect that the change in instructional approach was not a new one. These teachers were aware of the approach and had been implementing it on their own. These responses reflect a strength of conviction about using the Integrated whole Language approach. The descriptions for teachers with implementation scores of 13 reflect more diversity. These responses included phrases such as: 
"Positive, using Whole Language before the school made the change."

"Mixed feelings. However, immense immersion in process . . workshops."

"Liked the idea, but the change was difficult." These responses ranged from familiarity to hesitation and difficulty. The four teacher responses with low implementation scores reflect a lack of awareness of the instructional approach and a perception of being isolated while working on the implementation. The responses of teachers with low implementation scores will be presented individually with interpretations. One teacher responded, "The main change was a provision of novels instead of basal readers." This response reflects a limited understanding and use of the Integrated Whole Language approach. Another teacher responded "Life was too traumatic to think about the change." This responses is a reflection of this teacher's personal life and may indicate lack of attention to the implementation. The third teacher had moved out of state so interview data was not available.

\section{Differences Between Schools}

Any school and district differences are due to the influence of the outlyers. They appear to be related to the unique characteristics of the individual teachers, rather than school or district influences. Figure 2 and Table I display differences in teacher implementation scores by 
schools and districts. In order to elaborate on some of the patterns of difference, a descriptive analysis was used. Those schools previously described in response to question one as having congruency and those schools with differences in administrator and teacher interview responses were analyzed. One additional school in which only teachers were interviewed and whose responses indicated diversity of implementation was used in this analysis. Figure 3 displays the implementation scores for those selected schools.

Teacher

Implementation

Scores

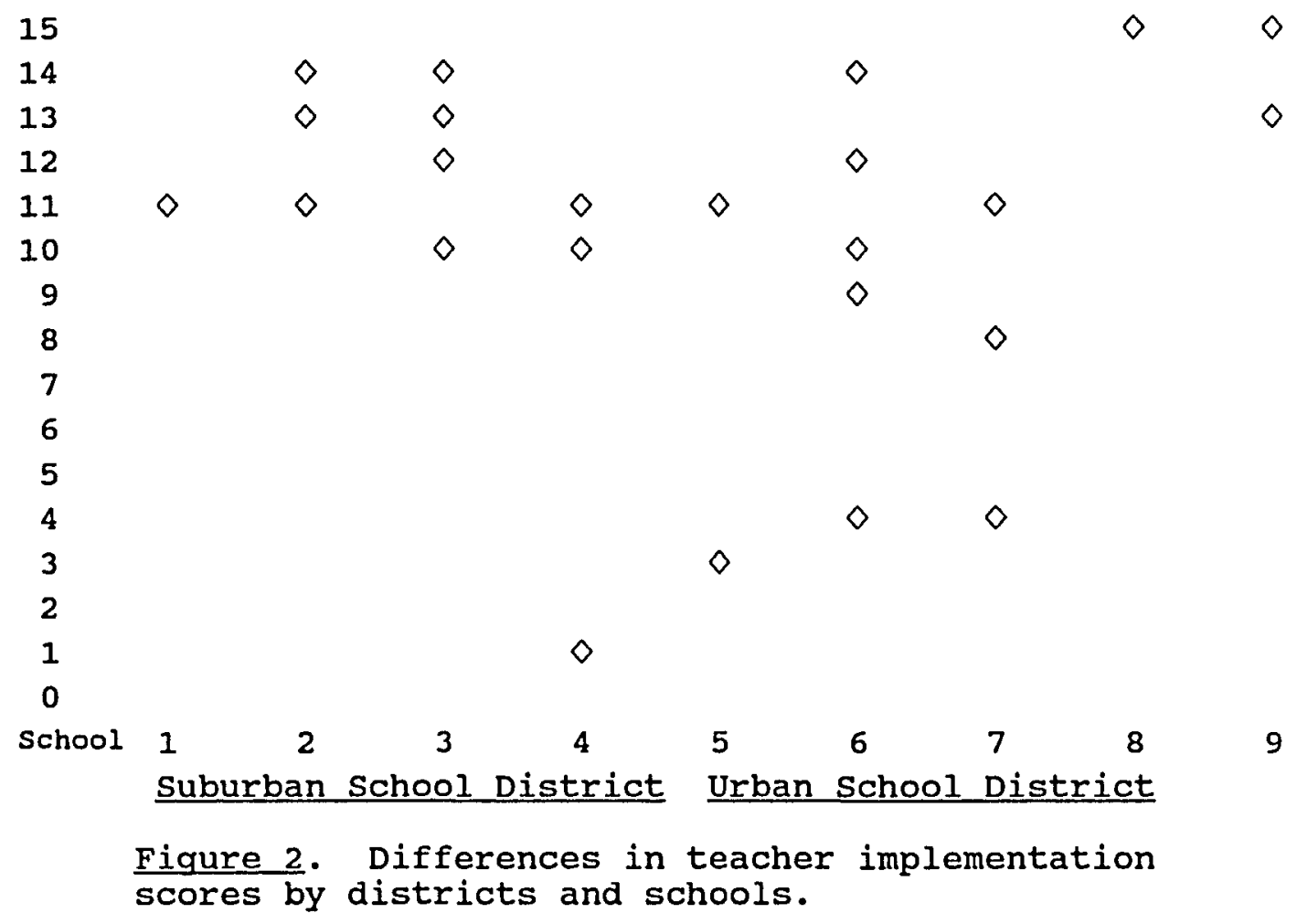


TABLE I

DIFFERENCES IN TEACHER IMPLEMENTATION SCORES REPORTED IN PERCENTAGES FOR DISTRICTS

"IDEAL PROFILE"

URBAN DISTRICT \& (Teachers)
SUBURBAN DISTRICT

\& (Teachers)

\begin{tabular}{rrrc}
\hline (low) & 1 & - & 9.1 \\
& 2 & $7 \overline{7}$ & - \\
3 & 7.7 & - \\
4 & 15.4 & $8 \overline{2}$ \\
9 & 7.7 & 27. \\
10 & 7.7 & 9.1 \\
11 & 23.7 & 8.2 \\
12 & 7.7 & 8.2 \\
13 & 7.7 & - \\
\hline
\end{tabular}

School

Number

1

9

6

7

2

$\begin{array}{lllllllllllllll}1 & 2 & 3 & 4 & 5 & 6 & 7 & 8 & 9 & 10 & 11 & 12 & 13 & 14 & 15\end{array}$ Implementation score

Figure 3. Differences in implementation scores for selected schools.

Schools 1 and 9 were those schools in which there was agreement within the administrator and teacher interview responses describing change. Their implementation scores 
show the same agreement. Schools 6 and 7 had the greatest differences in administrator and teacher interview responses describing the change. Their variety of implementation scores reflect this same disagreement. School 2 showed the strong teacher differences in interview responses describing the change, however the teachers implementation scores are grouped closer than those of Schools 6 and 7 .

overall, administrator and teacher interview responses describing the change were reflected in the teacher implementation scores. When there was agreement among administrators' and teachers' responses describing the change, the teachers' implementation scores were more closely grouped. Schools in which there were differences among administrator and teacher responses describing the change, had less agreement among teachers' implementation scores.

The difference within teacher interview responses in one school were not related to teachers' implementation scores (School 2). This could represent some of these teachers' need to communicate frustration, to acknowledge that the change was difficult. The teacher implementation scores within this school are 11, 13, and 14 which may be interpreted as evidence of strong attempts to understand and implement the Integrated Whole Language approach. Another interpretation of the differences between these teachers' interview data and their implementation scores could be that 
some of these teachers lacked confidence and were not aware of how well they were actually accomplishing change.

\section{Differences Between Districts}

Figure 2 shows the frequency distribution of teacher implementation scores by schools and by districts for the entire sample. The figure illustrates that only half of the schools are grouped closely in terms of teacher implementation scores. Table I shows the total percentage of teachers for each implementation level and the percentage for each district.

The implementation score for the suburban district are closely clustered with only one outlyer. The implementation score for the urban district are spread over the range of scores with five outlyers, two at the high level and three at the low level. When implementation scores of 10-15 are considered, the suburban district has a high proportion of teachers (10 of 11) implementing the change. The number of urban district teachers who scored at the levels of 10-15 was a lower proportion, 8 of 13 .

Interestingly, the qualitative data create a different picture than the implementation scores reveal. The suburban teachers talked more about the difficulties and the slow pace of the change when compared to the urban teachers (50\%). Urban teachers talked more in terms of "already using" the Integrated Whole Language approach (36\%) when compared to the suburban teachers (16\%). 
Summary

There were differences among teachers' implementation scores. When comparing the quantitative and qualitative data, there was a consistency between teacher descriptions and implementation scores at the highest level. There was more diversity between the two data for teachers with middle level implementation scores. Descriptive data for teachers with low level implementation scores were consistent, reflecting a lack of awareness of the instructional approach and a perception of being isolated and unsupported. Differences or agreement between administrators' and teachers' descriptions of the change within individual schools was reflected in the diversity or congruence of implementation scores. However, within one school teacher diversity of descriptions did not reflect diversity of implementation scores. The implementation scores of the two districts reflected a difference in the spread of scores. The urban districts implementation scores were spread over a larger range than the suburban district scores which were closely clustered.

FINDINGS FOR QUESTION FOUR

Research Question and Analysis procedures

"Is there a relationship between the level of implementation and teacher characteristics/teacher demographics?" The chi-square statistic was originally 
planned for analysis of these data; however, sample size did not support use of the statistic. Frequency distributions were used to examine the relationships between implementation scores and teacher demographic data. Teacher demographics included age, gender, education, and number of years of teaching experience. Each demographic factor is displayed in relation to implementation scores in the figures that follow.

Relationship Between Implementation Score and Education

Figure 4 displays the differences in the educational levels of teachers in relation to their implementation scores. The majority of teachers with low implementation scores were educated at the bachelor's degree level; however the majority of teachers scoring from 9-15 were also educated at the bachelor's degree level.

Education

Levels

BA $\diamond \diamond \quad \diamond \quad \diamond \infty \infty \infty \infty \infty \infty$

MA $\diamond$ $\diamond \quad \diamond \diamond$

MA+ $\infty \diamond \diamond$

PHD

$\begin{array}{lllllllllllllll}1 & 2 & 3 & 4 & 5 & 6 & 7 & 8 & 9 & 10 & 11 & 12 & 13 & 14 & 15\end{array}$

Teacher Implementation scores

Figure 4. Education levels and implementation scores. 
Relationship Between

Implementation Score

and Years of Teaching

Experience

Figure 5 displays the differences in years of teaching experience in relation to implementation scores for the teachers in this study. All of the teachers with 1-4 years of teaching experience had implementation scores of 11 and 12. Although these are not the highest implementation scores, they are scores showing a moderate implementation. It is interesting to note that none of the teachers with the least amount of teaching experience were found with low implementation scores.

Years of

Experience

\begin{tabular}{|c|c|c|c|c|c|c|c|c|c|c|c|c|c|c|}
\hline $1+$ & & & & & & & & & & $\infty$ & $\infty$ & & & \\
\hline $5+$ & & & $\diamond$ & & & & & $\diamond$ & $\diamond$ & & $\diamond$ & 0 & $\diamond$ & \\
\hline $10+\diamond$ & & & & . & & & & & $\diamond$ & $\infty$ & & $\diamond$ & $\diamond$ & $\diamond$ \\
\hline $20+$ & & $\diamond$ & & & & & & & & & $\diamond$ & $\diamond$ & $\diamond$ & \\
\hline 1 & 2 & 3 & 4 & 5 & 6 & 7 & 8 & 9 & 10 & 11 & 12 & 13 & 14 & 15 \\
\hline
\end{tabular}

Figure 5. Teacher experience and implementation scores.

\section{Relationship Between}

Implementation Score

and Teacher Age

Figure 6 displays the differences in the ages of teachers in this study in relation to their implementation scores. Teacher age did not seem indicative of implementation scores. However, it is interesting to note 
that all the teachers with low implementation scores were over 40 .

Age

$-30$

$\diamond \quad 0$

$30+$

$\diamond \infty \infty \infty \infty$

$40+8$

$\diamond$

$\infty \diamond$

$50+$

$\diamond$

$\diamond \diamond$

$\diamond \diamond$

$\begin{array}{lllllllllllllll}1 & 2 & 3 & 4 & 5 & 6 & 7 & 8 & 9 & 10 & 11 & 12 & 13 & 14 & 15\end{array}$

Teacher Implementation Scores

Figure 6. Age and implementation scores.

Relationship Between

Implementation Score

and Teacher Gender

Figure 7 displays the gender differences of the

teachers in this study in relation to their implementation

scores. Although, there are more females with low

implementation scores, there appears to be a

disproportionate (1 of 6) amount of males in the low

implementation group. This compares with 2 of 17 females in

the low group.

\section{Gender}

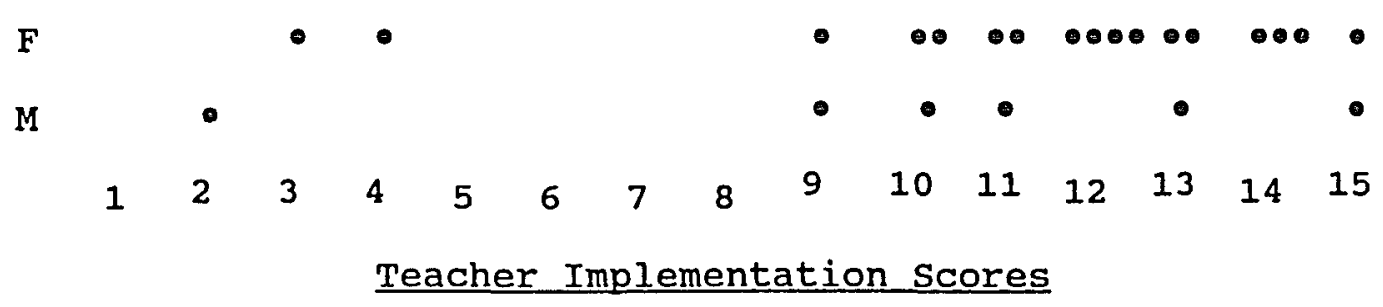

Figure 7. Gender and implementation scores. 
Summary

There were some interesting relationships between teacher implementation scores and teacher demographics. For example, teachers with low implementation scores had received fewer academic degrees. A distribution of years of teaching experience was found among the low implementation scores and the high implementation scores. As a group, teachers with less than five years of experience did not have low implementation scores. All of the teachers with low implementation scores were over 40 . Although there were more females with low implementation scores, there is a disproportionate amount of males with low implementation scores.

FINDINGS FOR QUESTION FIVE

Research Question and Analysis

Procedures

"Is there a relationship between implementation scores of the teachers and contextual factors in the educational settings (school district differences)?" Mini cases of the districts are provided as context for the analysis of differences. District implementation scores were analyzed for differences and the presence or absence of differences were examined via the contextual data.

There were no statistically significant differences found between the two districts. There were differences found between individual teachers, specifically with the 
highest implementation scores $(15,14$, and 13) and those with the lowest implementation scores $(1,2$, and 4). These differences play an influential role in comparison of the districts. Before, viewing the differences, mini cases of each district were developed.

\section{Mini Case of the Urban District}

The urban school district is the largest school district in the northwest section of the United states of America. It encompasses 152 square miles and includes 82 regular schools and 23 special and alternative schools. There is a student enrollment of 54,904 with $79 \%$ of the graduates continuing on to higher education. The overall minority enrollment is $28 \%$. Most of the district is in a moderate sized city (population 437,000 ); however, small portions of the surrounding counties are incorporated. The district employs around 2,100 "full-time support personnel" (administrative, clerical, cafeteria, custodial, and transportation) and around 2,900 full-time classroom teachers. Additionally, there is a daily average of 250 substitute teachers. Total annual funding for the district is around 446.4 million dollars.

The district's goals for students (as stated in their literature) is to teach the basic skills of reading, writing, speaking, computing, and comprehending at a level appropriate for further education and career advancement. The district provides a substantial amount of literature to 
the schools in the areas of reading and writing. The publications include the district's goals for these areas and research updates supporting the type of instruction promoted. The literature also offers ways in which the administration and support staff can provide leadership for instruction. Several publications are targeted for teachers to aid them in conducting parent teacher conferences explaining the new instructional approaches and the consequent lack of magazine tests.

\section{Urban Elementary School}

Demographics

For the purpose of this study the elementary schools in the urban district were examined more extensively. There are 62 elementary schools $(\mathrm{PK}-5)$. Over half of the district's total enrollment $(54,904)$ are elementary students. Each elementary school has a child development specialist. The five schools participating in this study have low minority enrollments (11\% to $22 \%$ ), an average of 510 students per school and an average class size of 25 students.

\section{Urban Fifth Grade student} Demographics

The mean age of fifth grade students participating in this study is $11 ; 31 \%$ are 10 years old, 60.98 are 11 years old, and $7.4 \%$ are 12 years old. Within the five schools 47.7\% of the fifth grade students are male and $52.3 \%$ are 
female. The reading comprehension scores for 1989 (one year after the implementation had begun) had a mean achievement level of $X=62.74(S D=18.5)$. The mean achievement level taken from comprehension scores one year later was $x=61.7$ $(S D=20)$. The SES was taken from the Teacher Questionnaire (see Appendix B). Of the 13 participating teachers in the urban district, 8 teachers reported that 16 students receive "free or reduced" lunch.

\section{Urban Fifth Grade Teacher}

\section{Demographics}

Thirteen fifth grade teachers from five schools in the urban district participated in this study. Within the teacher sample, $64 \%$ are female and $21 \%$ are male. Within the teacher sample, $14 \%$ of the teachers are less than 30 years of age, $36 \%$ are between 30-40, $14 \%$ between 40-50, and $21 \%$ over 50 years of age. The average education at level of participating teachers is a bachelor's degree (80\%). The mean years of teaching experience is 12.9 years. The majority of the teachers had completed inservice instruction within the last year or within the last one to three years. However, one teacher reported no inservice within the last 5-10 years and did not list an Integrated whole Language inservice. This teacher reported planning to take an inservice within the next year. The majority of teachers reported completing an Integrated Whole Language inservice and $64 \%$ said they planned on taking inservice in the future. 
Organizational Factors Related

to Change

For the urban district, the decision to implement an Integrated Whole Language program was brought about at both the district and the school level. The curriculum Committee, a teacher committee which selects materials for a six year time period, initiated the change at the school level. The Language Arts Specialists initiated the change at the district level. The majority of teachers reported that the change was initiated by the district, but that the district, principal, and teachers were involved in the decision to change. The change was reportedly communicated to teachers through staff meetings, printed material, and workshops. Most teachers reported adequate resources were provided. The resources included in their responses were, inservice, workshops, demonstration teaching, and ample funds for teaching materials. Teachers also reported that there were district and school level "experts" in the whole Language field. About $75 \%$ of the teachers reported the principal's role was both administrator and instructional leader. These responses portrayed the principals as very involved, giving support, encouragement and being knowledgeable about the approach. However, about $25 \%$ of the teachers reported the principal's role was strictly administrative and organizational. The administrator, principal, and teacher sample reported both district and principal support. 
Mini Case of the Suburban

District

The suburban school district includes 16 schools located in a small city $(47,000)$. The district covers 179 square miles, the boundaries reach well outside the city limits to rural farming areas. There are 16 schools and 7,300 students enrolled. The minority enrollment is $7 f$. The average class size is around 25. Seventy-five percent of the graduates go on to post secondary education. The personnel consists of 550 teachers ( $60 \%$ hold master's degrees), 400 support personnel, and 37 administrators. The annual funding for the district is around 38.7 million dollars. The district's curricular philosophy is that basic skills are emphasized throughout the district and across subject matter.

\section{Suburban Elementary School} Demographics

For the purpose of this study we will now look at the elementary schools. The teaching philosophy is towards individual creativity and basic skill growth. All the elementary schools have libraries, art, and music specialists and trained counselors. Learning Centers are found in most of the schools, and those without have access to other schools. The district has ten elementary schools $(K-5)$ with an enrollment of 3,600 students. There are 202 elementary teachers and the average class size is 25 students. 
Suburban Fifth Grade student

Demographics

The average age of the fifth grade students participating in this study is $11 ; 32.7 \%$ are $10,60.7 \%$ are 11, and 5.6\% are 12 years old. One student in the sample is nine years old. Forty-nine point five percent of the students are male and $50.5 \%$ are female. The reading comprehension scores for 1989 (one year after the implementation had begun) had a mean achievement level of $61.4(S D=18.1)$. The mean level of achievement taken from reading comprehension scores one year later was 62.74 (SD = 19.1). The SES was taken from the Teacher Questionnaire (see Appendix B) . Of the 11 participating teachers, 8 teachers responded to question 19 with a total of 31 students receiving "free or reduced lunches" (see Appendix B) .

Suburban Fifth Grade Teacher Demographics

Eleven teachers from four schools in the suburban district participated in this study. Within the teacher sample, $73 \%$ are female and $27 \%$ are male. Within the teacher sample $55 \%$ of the teachers are between the age of $30-40$ years, $27 \%$ between $40-50$, and $18 \%$ over 50 . The average education received by most teachers is a bachelor's (36\%) or a master's (36\%) degree. Within this teacher sample, $18 \%$ had received continuing education after their master's degree and $9 \%$ had received a doctorate. The mean years of 
teaching experience is 11.46. The majority of teachers had completed inservice instruction within the last year and over half (64\%) planned on inservice in the future. The majority of teachers reported completing an Integrated Whole Language inservice.

\section{Organizational Factors Related}

to Change

The change was initiated in the suburban district by the Elementary School Specialists and the Language Arts Committee, a teacher committee. The decision to change involved the Language Arts specialists, the Curriculum Committee, and the Language Arts Committee. As reported by teachers, the change was communicated to teachers through inservice, workshops, and printed communication. Most teachers reported adequate resources, but felt that there could have been more. The teachers reported resources such as workshops, inservice, district classes and meetings, but not enough funding for materials and time for preparation. The majority of teachers reported experts in the whole Language area at the district level who were involved in the inservice instructions, but no experts in the schools. Teachers reported the principal's role was that of administrator, providing resources and information. The administrator, principal, and teacher sample reported district support. However, the majority of the sample felt there was only partial support from the principals. 


\section{Differences Between Districts}

Both districts are fairly equivalent in terms of students age, student gender, and student achievement. The student SES appears to be lower in the sample of the suburban district, with 16 students in eight classes in the urban district receiving "free or reduced lunch" and 31 in eight classes in the suburban district. The teachers in both districts are comparable in age and gender, with the teachers in the suburban district being slightly older. Teachers in the suburban district had received more formal education than the teachers in the urban district. The majority of teachers in both districts had received inservice within the last year or within the last one to three years and most teachers planned on more inservice. The written or published contextual data sent in by each district revealed much more information was given to teachers in the urban district regarding reading research and literature concerning the implementation of the Integrated whole Language approach at the fifth grade level. The teacher reported resources also reveal that much more written information was given to the teachers in the urban district. The decision for change involved district and school level staff and teachers in both districts. The change was communicated to teachers by inservice, workshops, and printed communication in both districts. The teachers in the urban district reported satisfaction with the 
resources available and were aware of whole Language "experts" at the district and school levels. The teachers in the suburban district felt that there could have been more resources and described a lack of funding for material and time for preparation. More teachers in the urban district described the principal's role as including that of instructional leader. overall, administrators, principals, and teachers in the urban clistrict felt there was support for the change from both the district and the principal. The suburban teachers felt the principal's role in the change was one of administrator, providing materials but not encouragement. The overald. sample in the suburban district reported district support but not enough principal support.

Analysis of Teacher Implementation Scores in the Context of District Descriptions

The lack of student differences prevents using student data in analyzing the districts. This prompts a focus on teacher differences. The only possible difference between districts was an indication of less formal education, that is, advanced degrees, in the urban/district. There does not appear to be any relationship between implementation scores and this characteristic of districts.

The urban teachers reported more information, more support, and more inservice. Their responses indicated a satisfaction with these factors of implementation. However, 
their scores indicate a more individual process. The suburban teachers reported less satisfaction with the same factors and less comfort with the implementation. However, their scores are clustered at a mid to high level. The newness of the approach and their developmental stage in using it may have prompted a need for more support out of their own insecurity. This could also be related to their perception of the principal's role.

\section{FINDINGS FOR QUESTION SIX}

Research Question and Analysis Procedures

"How do students describe their attitudes and behaviors during the first year of implementation?" A descriptive analysis of students' responses to the questionnaire items was conducted. One item was inserted in the student questionnaire to assess student honesty in responding and is included in the findings. Two items asked for student demographics, age and gender. These questions generated information for question five.

\section{Student Honesty in Responding}

To assess student honesty in responding, students were asked if they liked to ride a bike. Seventy-one percent of the sample replied "often" and 28.48 replied "sometimes." This indicated that students were responding honestly. 


\section{STUDENT DESCRIPTIONS OF ATTITUDES AND BEHAVIORS TOWARD LANGUAGE ARTS}

\section{Reading Activities}

Overall, the students responses to the questionnaire revealed that they liked to read. Across the sample 55.6\% reported that they "liked to read often," $41.1 \%$ reported "sometimes," and $3.3 \%$ reported "never."

\section{Writing Activities}

The majority of students $(67.2 \%)$ responded that they liked writing projects "sometimes," with only $24.9 \%$ replying "often" and $7.9 q$ with "never."

Free Time in School and at Home

Most students (42.3\%), when given free time in school chose to talk with friends, and $31.2 \%$ chose to read a book as their second choice. When given "free time" at home, most students chose to play with their friends $(37.2 \%)$, do their homework (24.3\%), or watch television (17.4\%).

Books Read and Time Spent Reading outside of School

When asked, $97.1 \%$ of the students listed what they had read within the last month and $49.5 \%$ replied that they had read between one to five books in the last month. The majority of students (67\%) replied that they had read for more than 30 minutes outside of school during the week and $66.6 \%$ replied that they read outside of school because they 
wanted to. When asked, $99.2 \%$ of the students were able to give the title of the last book they read and $95.8 \%$ were able to list their favorite book.

\section{Differences Between Districts}

When the student responses are grouped into districts, there is not a significant difference between the two districts. The overall sample of students are roughly equivalent in their responses. Writing activities were less favored than reading activities, that is, most students reported liking to read "often" and liking to write "sometimes."

\section{FINDINGS FOR QUESTION SEVEN}

Research Question and Analysis Procedures

"Is there a relationship between students' attitudes and behaviors related to reading and writing and their teachers' implementation scores for the Integrated whole Language instructional approach?"

The original analysis procedures, chi-square and Pearson Product Moment, were considered inappropriate at the time of the data analysis. The Wilcoxon one-Way Analysis (Pratt \& Gibbons, 1981; Sprent, 1989) was used instead, because the numbers were small and because there were outlyers in teacher implementation scores. Because of these two factors, the data needed to be analyzed using a median 
rather than a mean. Data on student responses to the student questionnaire were generally rankings, so the Wilcoxon was an appropriate procedure with which to analyze for relationship with teacher implementation scores. The Wilcoxon procedure showed significant relationships between teacher implementation scores and student responses to questions in the student questionnaire. Two of the questionnaire items were asked to check for student honesty. Analysis of those items was not included in this report, but the results did indicate student sincerity in responding to the questions. Two questions asked for demographic information, age and gender. Analysis of those items was not included because the study did not seek relationships for these factors.

To display the data used for the wilcoxon analysis, scattergrams of the most significant student responses of attitudes and behaviors related to reading and writing have been developed. They are displayed in Appendix $D$.

The first question asks students to rank how often they prefer to read. Students were given choices of "often," "sometimes," and "never." When the data on student responses to this question were analyzed for a relationship with the teacher implementation scores, the wilcoxon procedure showed a statistically significant relationship. The $\mathrm{Z}$ score equals -19.3631 and the significance level was $\mathrm{P}$ $=.00001$. This statistic indicates that teachers with high 
implementation scores have students who read often. A scattergram (1) of this data displays the student responses to this question in relation to teacher implementation scores (see Appendix D).

The second question asked students to rank how often they prefer writing assignments. Students were given choices of "often," "sometimes," and "never." students responses to this question were analyzed for a relationship with teacher implementation scores. There was a statistically significant relationship. The level of significance was $\mathrm{P}=.00001$ and the $\mathrm{Z}$ score equals -19.4109 . This statistic means that teacher implementation scores are related to how often students choose to write. A scattergram (2) of this data displays the student responses to this question in relation to teacher implementation scores (see Appendix D).

For the fourth question students were asked to rank choices of free time activities in school. There was a statistically significant relationship between student responses to this question and teacher implementation scores. The level of significance was $\mathrm{P}=.00001$ and the $\mathrm{Z}$ score equals -18.8609 . A scattergram (3) of this data displays the student responses to this question in relation to teacher implementation scores (see Appendix D). When this data is viewed in the scattergram, more students who 
choose to read are in classrooms with teachers with high implementation scores.

The fifth question asked students to again rank free time activities in school after eliminating their first choice from the previous question. There was a statistically significant relationship between student responses and teacher implementation scores. The level of significance was $P=.00001$ and the $Z$ score equals -18.5594 . A scattergram (4) of this data displays the student responses to this question in relation to teacher implementation scores (see Appendix D).

Question six asked students to rank their choices of free time activities at home. The relationship between student responses and teacher implementation scores was statistically significant at level $\mathrm{P}=.00001$ and the $\mathrm{Z}$ score equals $-18 \cdot 6142$. When this data is viewed in the scattergram, more students who choose to read are in classrooms with teachers with high implementation scores (see Appendix D) .

Students were asked to rank choices of free time activities at home a second time after eliminating their first choice from the previous question in question seven. The relationship between student responses and teacher implementation scores were statistically significant at level $\mathrm{P}=.00001$. The $\mathrm{Z}$ score equals -18.6142 (see Appendix D) 
Students were asked to supply a list of everything they had read within the last month for question eight. Students were ranked as responding and not responding. There was a statistically significant relationship between student responses and teacher implementation scores. Level of significance was $P=.00001$ and the $z$ score equals -19.0821 (see Appendix D). Those students who could name reading material were in classrooms with teachers with high implementation scores. Those students who could not name anything specific were in classrooms with teachers with low implementation scores.

Question 10 asked students how many books they had read within the last month. Students responses and teacher implementation scores had a statistically significant relationship at the $P=.00001$ level and the $\mathrm{Z}$ score equals -19.0576. When this data is viewed in the scattergram (5), it is evident that there is a relationship between number of books read and teacher implementation scores (see Appendix D) .

Students were asked how much time they spent outside of school reading and answered in terms of levels of time in question 13. There was a statistically significant relationship between teacher implementation scores and student responses at the $\mathrm{P}=.00001$ level of significance. The $\mathrm{Z}$ score equals -18.7369 . When this data is viewed in the scattergram (6), it is evident that there is a 
relationship between amount of time spent reading by students and their teacher's implementation scores (see Appendix D) .

For question 14, students were asked why they read last week and given response choices. Student responses and teacher implementation scores were found statistically significant at the $\mathrm{P}=.00001$ level and the $\mathrm{Z}$ score equals -19.0797 (see Appendix D). A large number of students who indicated that they read because "they wanted to" were in classrooms of teachers with high implementation scores. Question 15 asked students to supply the title of the last book they had read. Students were ranked by response or no response. A statistically significant relationship was found between teacher implementation score and student responses. The level of significance was $P=.00001$ and the $\mathrm{Z}$ score equals -18.7650 (see Appendix D) .

students were asked to write the title of their favorite book for question 16. Students were ranked by response or no response. The relationship between teacher implementation and student responses was statistically significant at the $\mathrm{P}=.00001$ level and the $\mathrm{Z}$ score equals 18.7250 (see Appendix D) .

Summary

The wilcoxon procedure showed a level of significance for 12 of the 12 appropriate student response items on the questionnaire for a relationship with teacher implementation 
scores. These statistically significant findings

demonstrate a relationship between teacher implementation scores and student attitudes and behaviors related to reading and writing.

\section{SUMMARY}

Many of the findings provide strong support for the concept of change as an individual process. Individual differences were found among teacher implementation scores and within descriptions of their responses to the change. There were differences within most individual schools in both interview data and implementation scores. Only two schools displayed consistency among teachers' and principals' responses and teacher implementation scores.

District differences in teacher implementation scores appear related to contextual differences. Those emerged as significant factors differentiating the two districts. They may explain the differences in implementation scores and descriptions of perceptions of the change.

student data did not indicate significant differences in demographics or behaviors and attitudes related to reading and writing. Consequently student data did not inform differences in district implementation scores. of significance was the relationship between teacher implementation scores and student responses indicating preferences and practices related to reading and writing. 
The inclusion of multiple perspectives and the descriptive context for viewing the data contributed to the value of the findings of this chapter. The findings extend awareness and understanding of implementation as a change process. 
CHAPTER V

CONCLUSIONS AND RECOMMENDATIONS

\section{INTRODUCTION}

\section{Study Purpose}

The purpose of this study was to describe the implementation of a major curriculum change (at the fifth grade level) in two different school district settings, an urban district and a suburban one. The major curriculum change examined in this study was a shift from traditional reading and language arts instructional approaches to an Integrated Whole Language Instructional approach. The implementation of this change was examined on the basis of self-reports by administrators, teachers, and students and was analyzed in the context of organizational factors in schools that have typically influenced change. These included school district demographics, decision making process, administrators' support, inservice training, the principal's leadership role, and resources available. Additionally, the study investigated the relationship between teachers' self-reported implementation behaviors and student self-reported attitudes and behaviors related to reading and writing. 


\section{Chapter contents and Format}

This chapter presents conclusions and recommendations relevant to the findings of this study. Each body of conclusions is reported in relation to the individual research questions. From there a synthesis of the conclusions is presented. Recommendations are made and presented for several audiences. Research has shown that the implementation process needs to be viewed from many perspectives in order to understand the process. This study uses the perspectives of several professional groups, therefore, it is appropriate that recommendations be presented for administrators, teachers, and program developers. Recommendations are also presented for future research efforts.

\section{CONCLUSIONS}

\section{Question 1}

Research Question. "How do teachers and administrators describe the change related to implementation of the Integrated Whole Language approach?" In responding to this question, an additional question was posed and addressed in the analysis; "Are there individual and group differences in the perceptions of change?"

Conclusions. Most of the administrator responses acknowledged individuality among teachers, but probably to a greater extent than the actual diversity found within 
teacher responses. Congruence between teachers' and administrators' descriptions of the implementation process was found in only one school in each district. There were significant differences found between principals' and teachers' responses within most individual schools. From this it can be concluded that the principals may not be well informed about individual teacher's perception and perhaps not involved in communication with the teachers throughout the implementation process.

Within the teacher sample there was some diversity in responses and contrasting themes emerged. The predominant theme was that most teachers had already been using the Whole Language approach and the implementation gave them the license to continue and alleviated the pressure of employing traditional methods. The second theme was one of insecurity caused by lack of experience and program structure. Considering the administrators' and the teachers' responses, it is conclusive that there are individual responses among the teachers and that administrators are aware of and acknowledge this. The research has shown that change is accomplished by individuals and this study extends support for this concept of change (Hall, Wallace, \& Dossett 1973). A significant difference between the administrators' and teachers' responses was the administrators' lack of Whole Language terminology or language in their descriptions. This could represent insufficient knowledge 
and involvement on the part of the administrators. This potential lack of knowledge and involvement on the part of the instructional leader could explain the insecurity of some teachers. Research has shown that administrative support, especially that of the principal, is a key factor in a successful implementation (Virgilio \& Virgilio, 1984). The diversity among teachers' responses and the differences between teachers' and administrators' responses show that teachers are still somewhat isolated in their classrooms even in a school and district-wide implementation effort. Even in the context of school-wide programs, as recommended by research literature for a more effective approach to change, teachers appear to be isolated from other teachers as they implement change (Little, 1987).

There were significant differences found between the two districts in terms of teacher responses. Around $50 \%$ of the suburban district expressed frustration about the change process, whereas only $25 \%$ of the teacher responses in the urban district expressed frustration. There were more teachers in the urban district "already using" the Integrated Whole Language approach and this could explain the smaller percentage of frustration in the change. These teachers were already using the approach and, possibly because of this, there was more teacher interaction about a common experience with Whole Language. This leads to the conclusion that support and collegial interaction results in 
positive expression and confidence about change. Because some teachers in the urban district were knowledgeable about Whole Language and were practicing elements of the approach before the formal implementation, it is concluded that teachers do follow their individual teaching philosophies while attempting to satisfy district requirements and recommendations.

\section{Question 2}

Research Question. "How do teachers describe their language arts instruction during the first year of implementation of an Integrated whole Language instruction approach?"

Conclusions. There was some diversity among the teacher sample in their descriptions of the Integrated whole Language approach. However, there was a significant difference in language found between the two districts. Every teacher in the urban district used "Whole Language" in their description of the change except one. Only $35 \%$ of the teacher descriptions in the suburban district used "Whole Language" in their descriptions and the teachers in one school in the suburban district used "traditional" in their description.

The majority of the teachers in the urban district reported already using the Integrated Whole Language approach and their descriptions reflected their procedures in implementation. The teachers in the suburban district 
expressed frustration directed toward the implementation. It is concluded that the implementation did not represent a significant change for teachers in the urban district because the teachers were familiar with the approach and excited that the restraints of a traditional approach had been taken away. However, within the suburban district, the frustration expressed was directed at the implementation and lack of clarity in the program. It is concluded that although the two districts were involved in the first year of implementation, teachers in the suburban district were experiencing more difficulties.

one conclusion that could be drawn about the differences between districts is that early stages of implementation as seen in the suburban district are typically difficult, confusing, and lack clarity. Those teachers in the urban district who had been practicing the Integrated Whole Language instructional approach prior to the district implementation were in a more advanced state of implementation and expressed contrasting sentiments of confidence and enthusiasm. Teachers in the urban district displayed more knowledge and classroom practice in their descriptions. It may be concluded that there is a relationship between the knowledge and skill level evidenced by teachers and the affect they express. 
Question 3

Research Question. "Are there differences between teachers, between schools, and between districts in level of implementation?"

Conclusions. In general there was congruence between teachers' self-reported implementation behaviors and their interview responses. In other words, what teachers said was related to what they were doing, as reported on the questionnaire. The only exception to this was found among teachers in the suburban district. Their implementation scores indicated that they were implementing the Whole Language approach but their interview responses indicated insecurity, difficulty, and impatience with the change process. This is a clear indication of the concept of change as a "developmental process" and it encompasses both attitudes and behaviors when a new program is implemented (Hall et al., 1973). This was truly a new process for teachers in the suburban district and they were just developing in "feeling and skills." The teachers in the urban district reported that they "had been using Whole Language," so they were probably more advanced in the developmental process. This may be why they sounded more comfortable.

These findings also support the conclusions that change is an individual process (Hall et al., 1973). The conclusion to be drawn from the findings at the school level 
is that in most of the schools there was a diversity in the perspectives of participants, both teachers and principals. In two schools, the response indicated a common language, a common perception, and some common sentiments. A more significant conclusion is that the implementation scores were aligned with either the diversity or the agreement in perception.

\section{Question 4}

Research Question. "Is there a relationship between the level of implementation and teacher characteristics/ teacher demographics?"

Conclusions. In general, teacher characteristics of age, gender, education level, and years of teaching experience appear to be only minimally related to implementation scores. Any additional conclusions about possible relationships can only be tentative due to the limited sample. It may be that the educational level of a teacher is not related to a teacher's ability or tendency to implement a new approach. It may be that a teacher's years of teaching experience is not an indication of ability or tendency to implement a new approach.

When teacher age is considered, it may be that as some teachers get older, they may resist or ignore change, or find it difficult to abandon methods they have been using. This can be interpreted as one of those human qualities that are important to study (Rist, 1982). 
With respect to teacher gender, the male sample is so small that it does not appear, to be appropriate to draw conclusions about the relationship between teacher gender and implementation scores.

\section{Question 5}

Research ouestion. "Is there a relationship between level of implementation and contextual factors in the educational settings (district differences, school differences) ?"

Conclusions. The findings indicate that teachers continue to be isolated in their classrooms even during district and school-wide implementation and that this isolation is a hindrance to change. There is indication from this study that teachers consider the principal's role a factor in reducing this isolation. Research has shown that the principal's role must be that of facilitator and instructional leader in implementation efforts. This study supports that conclusion. Those teachers in this study who perceive their principal as a supportive instructional leader, described minimal frustration and difficulty with the implementation process. Therefore it can be concluded that teacher frustration can be alleviated by principal communication, principal invalvement in and support of change. Again, those teachers who perceived ample support in terms of training, time, and materials described the implementation process positively. Therefore it can be 
concluded that financial support, materials, and time for planning should be provided for successful implementation. These provisions should be adequate and available to circumvent teacher frustration.

\section{Question 6}

Research Question. "How do students describe their attitudes and behaviors during the first year of implementation?"

Conclusions. The first conclusion appropriate for this question and the findings is that this sample of fifth grade students generally liked to read and write. They preferred to write less often than they liked to read. The students responded that they read because they wanted to. These fifth graders are probably typical in that their first choice when given free time in school is talking with friends. This was also their first choice when free time was available at home. These conclusions about student affect toward reading and writing indicated that the Integrated whole Ianguage approach would probably be positively received by students and have potential for success.

The second conclusion is that the student population in the two districts did not differ significantly in their preferences for reading and writing. This lack of difference in the student population indicates that 
differences in implementation is related to factors other than students.

\section{Question 7}

Research Question. "Is there a relationship between students' attitudes and behaviors and their teachers' level of implementation of an Integrated whole Language instructional approach?"

Conclusions. There is overwhelming evidence that teacher implementation scores are related to the attitudes and behaviors students described on the questionnaire. student preferences for reading and writing, time spent in reading activities, and amount of books read can be predicted by teacher implementation scores. Another way of stating these conclusions is that the findings in response to this question demonstrate that the implementation of Integrated whole Language approach is not negatively related to student reading and writing behaviors and attitudes.

\section{RECOMMENDATIONS}

All parties involved in the change involved in implementation efforts must be aware that change is an individual process and its success demands sensitivity to individual differences. 


\section{Administrators}

The first recommendation to administrators is a

reminder: the decision to bring about change must involve teachers. Teacher expertise must be recognized and utilized when making an instructional change. Involving teachers in the decision making process and building on teacher strengths promotes implementation. The change must then be accompanied by resources such as training, time, and materials to support teacher transitions. It is also recommended that administrators ensure program clarity and structure as a provision to teachers. It is recommended that administrators take a more active role in the implementation process and support communication with and among teachers. Change must be accompanied by a provision for teachers to interact, to share ideas, to hear others' perceptions, and to support each others' practices. This provision enables those teachers with some expertise or experience to assist those teachers who are experiencing the difficulties of real change. Inservice does make a difference to teachers, and teachers who are experiencing real change need and request such support. Administrators need to study a new approach to the same degree that teachers study the approach. The principal needs to first organize and facilitate the change, but also to provide instructional leadership to the change. To do this the principal must spend time in classrooms when an 
implementation is in process. This promotes the understanding and dialogue that accompany the instructional leader role.

Within the role of facilitator and instructional leader, principals need to be aware that change is an individual process and that individuals will respond differently. It is necessary for administrators to notice and be sensitive to insecurities of teachers during the change process and to provide the needed encouragement and support.

\section{Teachers}

When teachers are involved in change such as an implementation effort, they need to work collaboratively, to talk about the change and the implementation. Teachers need to support each other, to plan together for implementation, and share their experiences and difficulties, rather than remain in their typically isolated situations. Teachers need to be patient and understand that change takes time and is different for each individual. In terms of time, inservice, materials, and financial needs teachers need to demand support before, during, and after the change process.

It is recommended for teachers to pay attention to how they are feeling toward a change. When teachers are implementing at a high level, it is probable that teacher enthusiasm and commitment is communicated to students. It is likely that if teachers feel negative towards a change 
they are less likely to be open and may not put effort into the change. Just as teachers' enthusiasm and commitment may be communicated to students, the negativity and lack of enthusiasm may also be communicated to students.

\section{Program Developers}

Before a change is planned, program developers need to survey the teacher population to determine the range of instructional practices related to the approach to be implemented. They should involve teachers in the process of program development and planning. Because the change process takes time, program developers need to commit to long-term efforts with one instructional approach before initiating other changes. Program developers should also stay involved and informed in the implementation process. This would include talking with teachers and visiting classrooms. This kind of involvement may result in planning more inservices, different types of inservices, or other kinds of support for which teachers have indicated a need.

\section{Future Research}

Future research efforts should approach implementation with a longitudinal design. Long-term approaches are necessary to study the implementation process for significant findings. Teacher perceptions and descriptions must be a focus for understanding an implementation process. The principal's role is an important variable and should 
also be examined relevant to the progress or lack of progress in an implementation effort. There is a need for future research efforts to employ both qualitative and quantitative approaches to provide a thorough understanding of the implementation process. Future efforts must also address the need for alternative methodologies for the study of change in education settings and specifically the implementation process.

\section{SUMMARY}

The significant differences between administrator and teacher interview responses indicated limited knowledge of the approach on the part of district level personnel and principals' and principals' lack of participation. More teachers in the urban district were more comfortable with the change due to experience with the approach. The suburban teachers were more insecure due to the lack of experience and developmental growth. The suburban teachers' responses to the interview were typical of the beginning stages of change. The diversity of teacher responses to the interview also indicated that teachers are still somewhat isolated in their classroom. Administrators, teachers, and program developers need to be aware of this. This study provides specific recommendations to administrators, teachers, and program developers to promote 
more effective implementations in schools. Awareness and involvement are major themes in the recommendations.

The study of implementations of changes in curriculum and instruction demands increased efforts, large scale approaches, and alternative methodologies. The inclusion of multiple perspectives, a blend of quantitative and qualitative methodologies, and an approach of analyzing within a contextual framework characterize this study. Future studies are encouraged to take direction from the design and findings of this study to extend the knowledge base about implementation as change. 


\section{REFERENCES}

Alexander, J., \& Filler, R. (1976). Attitudes and reading. Newark, DE: International Reading Association.

Anderson, R., Hiebert, E., Scott, J., \& Wilkinson, I. (1985). Becoming a nation of readers. Washington, DC: United States Department of Education.

Ary, D., Jacobs, L. C., \& Razavieh, A. (1985). Introduction to research in education. Fort worth: Holt, Rinehart, and winston.

Ashley, J., \& Butts, D. (1970). A study of the impact of an inservice education program on teaching behavior. In D. P. Butts (Ed.), Research and curriculum development in science education (pp. 96-116). Austin: University of Texas at Austin, Science Education Center.

Bedrosian, V. (1983). The social emotional dimension of teacher student interactions during beginning reading instruction. (Doctoral dissertation, University of California, 1983). Dissertation Abstracts International, 44, 7-12.

Berliner, D. (1992, February 25-29). Educational reform in an era of disinformation. Paper presented at the annual meeting of the American Association of Colleges of Teacher Education, San Antonio, TX.

Berman, P., \& McLaughlin, M. W. (1978). Implementation of educational innovations. The Educational Forum, 40 (3), 345-370.

Biological Science Curriculum study. (1970). A formative evaluation of $\mathrm{ME}$, NOW--unit 1, digestion and circulation. Boulder: University of Colorado, Life Sciences for the Educable Mentally Handicapped.

Bohn, C., \& Raun, C. (1970). A study of teacher characteristics as predictors of successful implementations of an innovative curriculum. In D. P. Butts (Ed.), Research and curriculum development in science education (pp. 156-160). Austin: University of Texas, Science Education Center. 
Brophy, J., \& Good, T. (1969). Teacher-child dyadic interaction: A manual for coding classroom behavior. Austin: University of Texas, Research and Development Center for Teacher Education.

Burke, C. (1987). Reading interview. In Y. Goodman, D. Watson, \& c. Burke (Eds.), Reading miscue inventory: Alternative procedures (p. 134). New York: Richard C. Owen.

Butt, R., \& wideen, M. (1974, February 18-22). The development, validation, and use of an arbitrary implementation scale (AIS) as a /basis for ex post facto curriculum evaluation. Paper presented at the meeting of the American Educational Research Association, Chicago, IL.

Cappleman, H. (1983). A qualitative analysis of the reading comprehension and attitudes toward reading of first graders taught by teachers whose implicit theories of reading differ (Doctoral dissertation, Duke University, 1983). Dissertation Abstracts International, 44, 7-12.

Cohen, M. (1981, April/May). Effective schools: What the research says. Today's Education: Social studies Edition, 70 (2) , 34-37.

Coley, J. D. (1990). The good news and the bad news about whole language: A personal perspective (English Position Paper 120). (ERIC Document Reproduction Service No. ED 317 956)

Colvin, v. (1991). Differences in teachers descriptions of classroom practices. Unpublished manuscript, Portland State University, Portland, OR.

Commission on Science Education. (1965). AACS Competency Measure: Science--A process approach, parts 1 through 6 and commentary for teachers. Washington, DC: American Association for the Advancement of Science.

Conley, S. C., Schmidle, T., \& Shedd, J. B. (1988). Teacher participation in the management of schools systems. Teacher College Record, 90, 259-280.

DeFord, D. (1978). A Validation study of an instrument to determine a teacher's theoretical orientation to reading instruction. Unpublished doctoral dissertation, Indiana University. 
Dillon, D., \& O'Brien, D. (1992). Article content and authorship trends in The Reading Teacher 1948-1991. The Reading Teacher, 45 (5), 362-368.

Dillon, D., \& Searle, D. (1981). The role of language in one first grade classroom. Research in the Teaching of English, 15 (4), 311-328.

Doyle, W., \& Ponder, G. (1977). The practicality ethic in teacher decision making. Interchange, $\underline{8}, 1-12$.

Dreeben, R. (1973). The school as a workplace. In R. M. W. Travers (Ed.), Second handbook of research on teaching (pp. 125-160). Chicago: Rand McNally.

Durkin, D . (1983) . Teaching them to read. Boston: Allyn and Bacon.

Durkin, D. (1988). Teaching them to read (5th ed.). Boston: Allyn and Bacon.

Elmore, R., \& McLaughlin, M. W. (1982). Strategic choice in federal education policy: The compliance-assistance tradeoff. In A. Lieberman \& M. W. McLaughlin (Eds.), Policymaking in education, 81 st yearbook of the National Society for the study of Education (pp. 159194). Chicago: University of Chicago Press.

Fein, S., \& Solomon, A. (1990, April 16-20). The relationship between student reading achievement as measured by standardized test scores and reading attitudes as measured by students and teachers responses to selected national assessment of educational progress attitudinal items. Paper presented at the annual meeting of the American Educational Research Association, Boston, MA.

Fenstermacher, G. (1992, February 25-29). Tensions between educational goals and mechanistic approaches in schools. Paper presented at the annual meeting of the American Association of Colleges of Teacher Education, San Antonio, TX.

Fiedler, M. L. (1975). Bidirectionality of influence in classroom interaction. Journal of Educational psychology, 67 (6), 735-44.

Fox, R., Luszki, M., \& Schmuck, R. (1966). Diagnosing classroom learning environments. Chicago: Science Research Associates, Inc. 
Freppon, P. (1988). An investigation of children's concepts of the purpose and nature of reading in different instructional settings. Unpublished doctoral dissertation, University of Cincinnati, $\mathrm{OH}$.

Fullan, M. (1972, Summer). Education and adaptive capacity. Sociology of Education, 45 (3), 271-187.

Fullan, M., \& Park, P. (1981). Curriculum implementation: A resource booklet. Toronto: Ontario Ministry of Education.

Fullan, M. \& Pomfret, A. (1977). Research on curriculum and instruction implementation. Review of Educational Research, 47 (1), 335-397.

Gans, R. (1963). Common sense in teaching reading. Indianapolis: Bobbs-Merrill.

Gay, L. R. (1987). Educational research: Competencies for analysis and application (3rd ed.). Columbus, $\mathrm{OH}$ : Merrill.

Gibson, T. (1973). Teachers talking, aims, methods, attitudes to change. Great Britain: Allen Love.

Goodlad, J. (1975). The dynamics of educational change. New York: McGraw-Hill.

Goodman, K. (1986). What's whole in whole lanquage? Portsmouth, NH: Heinemann.

Goodman, K., \& Goodman, Y. (1986). A whole-language comprehension centered reading program in language and literature. Tucson: University of Arizona, Tucson College of Education. (ERIC Document Reproduction Service No. ED 210630 )

Hall, G., \& Loucks, S. A. (1978, September). Teacher concerns as a basis for facilitating and personalizing staff development. Teachers College Record, 80 (1), 36-53.

Hall, G., Wallace, R., \& Dossett, W. (1973). A developmental conceptualization of the adoption process within educational institutions. Austin: University of Texas, Research and Developmental Center for Teacher Education. 
Harp, B. (1988, November). When the principal asks: When do you do whole language instruction, how will you keep track of reading and writing skills? The Reading Teacher, 42 (2), 160-161.

Harste, J. C. (1977, May 2-6). Teacher behavior and its relationship to pupil performance in reading. Paper presented at the annual meeting of the International Reading Association, Miami Beach, FL.

Hatch, J. A., \& Freeman, E. B. (1988). Kindergarten philosophies and practices; Perspectives of teachers, principals and supervisors. Early Childhood Research Quarterly, $\underline{3}$ (2), 151-166.

Heck, S., Stiegelbauer, S. M., Hall, G. E., \& Loucks, S. (1981). Measuring innovation configurations: procedures and applications. Austin: Texas University.

Hickman, J. G. (1979). Response to literature in a school environment, grades $\mathrm{K}-5$. (Doctoral dissertation, Ohio State University, Ohio, 1979). Dissertation Abstracts International, 44, 7-12.

Huberman, M., \& Miles, M. (1984) . Innovation up close. New York: Plenum.

Huebsch, w. (1991, January 22-26). Utilizing tradebooks in the elementary school: Consideration and implications for change. Paper presented at the annual meeting of the International Reading Association, Las Vegas, NV.

Jenks, H. (1970). Factors affecting the adoption of change. In D. P. Butts (Ed.), Research and curriculum development in science education (pp. 171-202). Austin: University of Texas at Austin, Science Education Center.

Kelley, M. L., \& Chin, M. K. (1967). An experimental study of formal reading instruction at the kindergarten level. The Journal of Educational Research, 60 (5), 224-229.

Klein, S. S. (1971, May). Student influence on teacher behavior. American Educational Research Journal, $\underline{8}$ (3), 403-421.

Lehman, B. , \& Crook, P. (1988, April). Effective school's research and excellence in reading: A rationale for children's literature in the curriculum. Childhood Education, 64 (4), 235-242. 
Leithwood, K. A. \& Montgomery, D. J. (1982). A framework for planned educational change: Application to the assessment of program implementation. Educational Evaluation and Policy Analysis, 4 (2), 157-167.

Little, J. (1981). School success and staff development: The role of staff development in urban desegregated schools. Boulder, Co: Center for Action Research.

Little, J. (1987). Teachers as colleagues. In V. Richardson-Koehler (E'd.), Educators handbook: A research perspective (pp. 491-518). New York: Longman.

Loucks, S., \& Lieberman, A. (1983). Curriculum implementation. In F. W. English (Ed.), Fundamental curriculum decisions । (pp. 126-141). Alexandria, VA: Association for Supervision and Curriculum Development.

Louis, K. (1981, November 12). Implementing research and development in schools: state of the art. Paper presented at the regional forum "Improving Basic Skills using Research and Development" of the Appalachia Educational Laboratory, Charleston, WV.

Mahlios, M., \& Bromley, K. (1984, January-February). student and teacher bidirectional classroom behavior: Effects on classroom interaction, achievement, and attitude. Paper presented at the annual meeting of Teacher Educators, Néw orleans, LA.

May, F. (1990). Reading as communication: An interactive approach (3rd ed.). Columbus, OH: Merrill.

McLaughlin, M. (1987). Learning from experience: Lessons from policy implementation. Evaluation and Policy Analysis, $\underline{9}(2), 171-178$.

Merriam, S. B. (1988). Case study research in education: A gualitative approach. San Francisco: Jossey-Bass.

Mohlman, G., Coldarci, T., \& Gage, N. (1982). Comprehension and attitude as predictors of implementation of teacher training. Journal of Teacher Education, 33 (1), 31-36. 
Moore, S., Wideman, M. E., \& Dilling, H. J. (1984). Curriculum implementation: A survey of teachers' level of use of "the program and the six year old" and "social and environmental. studies (grades 5-6) guides. (Research Report/Reports-Technical, 143). Ontario, Canada: The Research Centre, Scarborough Board of Education. (ERIC Document Reproduction Service No. 291612 )

Navin, S., \& Bates, G. W. (1986). Improving attitudes and achievement of remedial readers: A parent counseling approach. Elementary School Guidance and Counseling, 21 (3), 203-209.

Neale, D. C., Gill, N., \& Tismer, W. (1970). Relationship between attitudes toward school subjects and school achievement. The Journal of Educational Research, 63 (5), 232-237.

Nistler, R., \& Shepperson, G. (1990, November 27-December 1). Exploring new directions of staff development: Teachers in charge of change. Paper presented at the annual meeting of the National Reading Conference, Miami, FL.

Noble, C. G., \& Nolan, J. D. (1976). Effect of student verbal behavior on teacher behavior. Journal of Educational Psychology, 68 (3), 342-346.

Norris, P. J. (1990). Children at risk program (C.A.R.P.): reeling kids in through reading (Practicum Paper 043). Fort Lauderdale: Nova University. (ERIC Document Reproduction Service No. 323 500)

Persall, J. (1972). An assessment of the instructional and organizational innovations implemented in a selected school system. Unpublished doctoral dissertation, Auburn University, Auburn, AL.

Phillips, I. (1990, December 12-15). "Weaving a web" of literacy: A one-year evaluation of the implementation of a literature based whole lanquage approach. Paper presented at the annual meeting of the American Reading Forum, Sarasota, FL.

Prater, D., \& Terry, C. (1985, March 31-April 4). The effects of composing model on fifth grade students reading comprehension. Paper presented at the annual meeting of Educational Research Association, Chicago, II. 
Pratt, J. W., \& Gibbons, J. D. (1981). Concepts of nonparametric theory. New York: Springer-Verlag.

Richards, H. C., \& Bear, G. G. (1987) . Stability and criterion related validity of the estes attitude scales. Educational and Psychological Measurement, 47 (2), 493-498.

Richardson, V. (1990). Significant and worthwhile change in teaching practice. Educational Researcher, 19 (7), 10-18.

Rist, R. (1982). Introduction. In R. Bogdan \& S. K. Biklen (Eds.), Qualitative research for education: An introduction to theory and methods (pp. ix-xi). Boston, MA: Allyn and Bacon.

Rogers, E. M. (1965). Diffusion of innovations. New York: Columbia University Teachers College, Bureau of Publication.

Rosenholtz, S., Bassler, O. \& \&oover-Dempsey, K. (1986). Organizational conditions of teacher learning. Teaching and Teacher Education, $\underline{2}$ (2), 91-104.

Rowan, B. (1990). Commitment and control: Alternative strategies for the organizational design of schools. In C. B. Cazden (Ed.), Review of Research in Education (pp. 353-389). Washington, DC: American Education Research Association.

Sanacore, J. (1990). Administrative guidelines for supporting the whole language philosophy (Report No. 010 286). (ERIC Document Reproduction Service No. 324 665)

Sarason, S. (1971). The culture of the school and the problem of change. Boston: Allyn and Bacon.

Schmidt, W., Roehler, L. R., Caul, J. L., Diamond, B., Solomon, D., Cianciolo, P., \& Buchmann, M. (1983). Curriculum integration: Its use in lanquage arts instruction (Research Series No. 140). East Lansing: Michigan State University, Institute for Research on Teaching. (ERIC Document Reproduction Service No. 241 942)

Shepard, L. (1991, November 14-16). Preparing empowered teachers for curriculum change. Paper presented at the annual meeting of National Association of Early Childhood Teacher Educators. Denver, $c o$. 
Sieber, S. D. (1979). Incentives and disincentives for knowledge utilization in public education: A synthesis of research. San Francisco: Far West Lab for Educational Research and Development. (ERIC Document Reproduction Service No. 203 457)

Siera, M. \& Combs, M. (1990). Transitions in reading instruction: Handling contradictions in beliefs and practice. Reading Horizons, 31 (2), 113-126.

Sparks, G. (1988). Teachers attitudes toward change and subsequent improvements in classroom teaching. Journal of Educational Psychology, 80 (1), 111-117.

Sprent, P. (1989). Applied nonparametric statistical methods. London: Chapman and Hall.

Stallings J., \& Mohlman, G. (1981). School policy, leadership style, teacher change, and student behavior in eight schools: Final report. Washington, DC: National Institute of Education.

Stephens, D. (1991). Research on whole lanquage, support for a new curriculum. Katanoah, NY: Richard C. Owen Publishing Inc.

Stephens, T. (1974, Winter). Innovative teaching practices: Their relation to system norms and rewards. Educational Administration Quarterly, 10 (1), 35-43.

Tobin, K. (1987). Forces which shape the implemented curriculum in high school science and mathematics. Teaching and Teacher Education, $\underline{3}$ (4), 287-298.

Virgilio, s., \& Virgilio, s. (1984). The role of the principal in curriculum implementation. Education, $104(4), 346-357$.

Washington University. (1970). An evaluation of a project for the analysis, development, implementation, and diffusion of the new social studies curricula. st. Louis: Missouri Center for Educational Field studies.

Watson, D. J., Crenshaw, S., \& King, D. (1984, May 6-10). Two approaches to reading: Whole lanquage and skills. Paper presented at the annual meeting of the International Reading Association, Atlanta, GA.

Wise, A. (1988, March 25). Restructuring schools. Presentation at the Annual Georgia Leadership Institute, Athens, GA. 
Wolcott, H. (1977). Teachers vs. technocrats. Eugene: University of oregon, Center for Educational Policy and Management.

Yin, R. (1981, January/February). Life histories of innovations: How new practices become routinized. Public Administration Review, 41 (1), 21-28. 
APPENDIX A

ADMINISTRATOR AND TEACHER

INTERVIEW QUESTIONS 
CHANGE PROCESS/CONTEXT OF IMPLEMENTATION OF HHOLE LANGUAGE INSTRUCTIONAL APPROACH AT THE FIFTH GRADE LEVEL: URBAN AND SUBURBAN BCHOOL DIBTRICTS

1. When you think back to the first year of the implementation of Whole Language (1987), when the district moved to Whole Language how would you describe the change that occurred . . ( (what they remember)?

2. Who initiated the change to whole Language? How did it get started?

3. Before the change to Whole Language did the district mandate how language arts was taught?

If "yes," what approach was mandated.

If "no," what did teachers do?

4. When did you first start hearing about Whole Language?

5. How was the change to whole Language communicated to you?

- to the school principal

- to the teachers

- to the district

6. Who was involved in the decision to change to whole Language?

7. How were they involved? (refer to previous answer)

8. What kind of support was provided to the teachers to help them make the change to whole Language?

- consultants (role)

- inservice (how much and how often)

- support materials (what kind)

- time to learn

- time to plan (how much, how often, and how long did it last)

- money for books-materials (how much per school, per teacher)

- money for time out to take classes, provided a substitute (how often)

was there any other kind of support?

9. (District) Does the district have any experts in the field of Whole Language?

(Principal and teachers) Does your school have any experts in the field of Whole Language? 
10. (Teachers) What was the principals role in the implementation?

(Administrators) What was your role in the implementation?

11. Did the change have administrative support?

- from district

- from principal? 
APPENDIX B

TEACHER QUESTIONNAIRE 


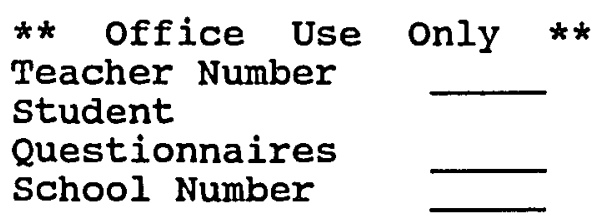

TEACHER QUESTIONNAIRE

1. Describe the approach you are using to teach language arts?

2. Overall, would you categorize this approach as: (Check only one)

1) Integrated Whole Language

2) Traditional Skill-based

3) Other (specify):

3. What inservice instruction have you completed in each of the following language arts components? list number of hours.

1) Phonics

2) Higher Level Thinking Skills

3) Whole Language/Integrated Curriculum

4) Use of Context Skilis

5) None

6) Other (specify) :

4. Do you have any published materials in your classroom for use with language arts?

1) Yes

2) No

If yes, what materials do you have?

5. If you have any published materials for language arts, do you use them?

1) Yes

2) No 
6. What are the strategies you use in your approach to language arts. Check all that apply.

1) Phonographemic (Phonetic Clues)

2) Semantic (Contextual and Meaning clues)

- 3) Syntactic (Grammatical clues)

7. Please indicate below the appropriate number of minutes, each day, your class is involved in the following language arts activities during your allotted language arts period. (\# of min.)

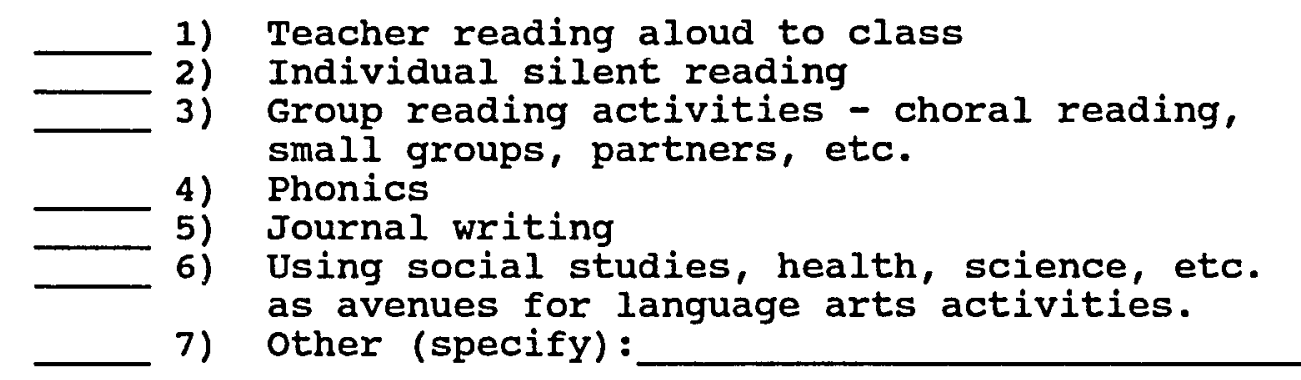

8. How many minutes do you spend daily teaching reading as a separate subject? (Check only one)

\begin{tabular}{ll}
\hline 1) & None \\
\hline 2) & Less than 30 \\
$30-40$ \\
4) & $40-50$ \\
5) & More than 60
\end{tabular}

9. How many minutes do you spend daily teaching formal reading/language/writing (listening, speaking, reading, and writing) as integrated subjects? (Check only one)

\begin{tabular}{ll}
\hline 1) & None \\
\hline 3) & Less than 30 \\
$30-40$ \\
\hline 4) & $40-50$ \\
5) & More than 60
\end{tabular}


10. What materials do students use when they are in your language arts period? (Rank, from 1-5, the five most actively used materials, "1" being the most used and "5" being the least.)

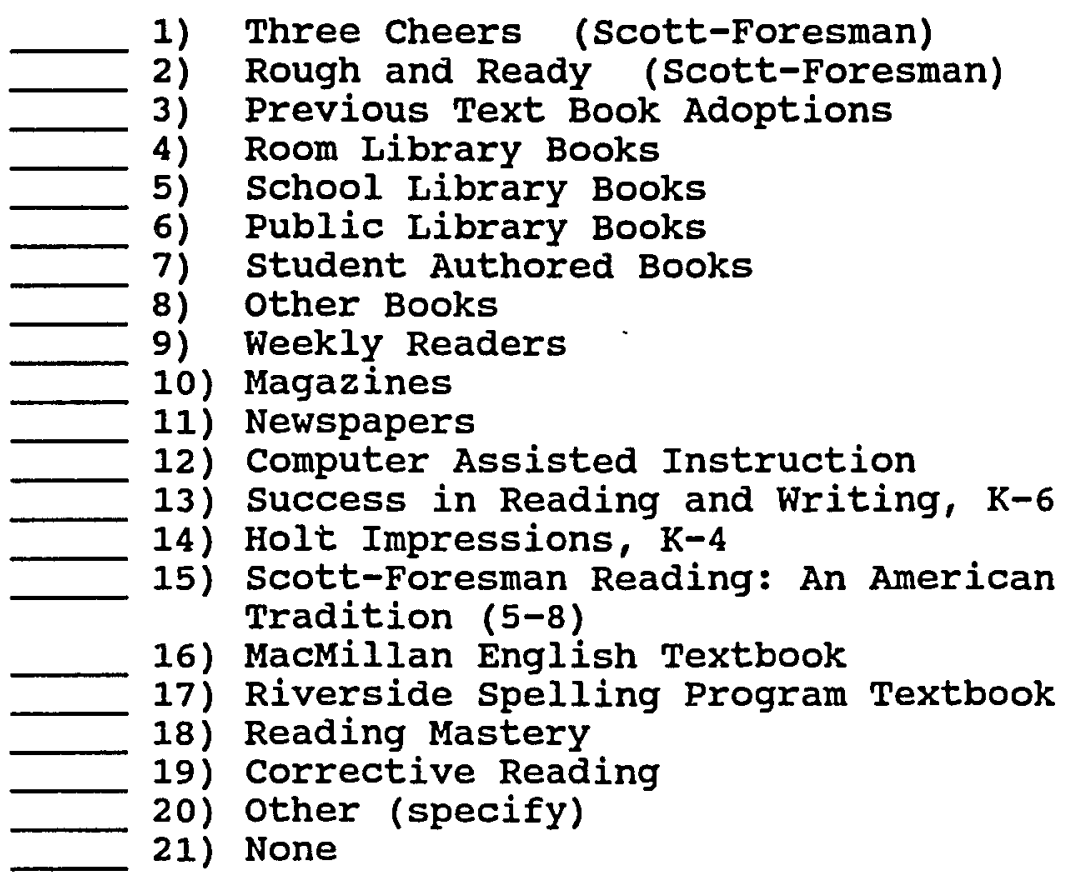

11. What textbook materials so you use in Reading?

Name of series:

Other (specify):

12. What textbook materials do you use in language arts? (Check none if no series is used.)

Name of series:

Other (specify):

None: 
13. What worksheets and supplementary materials do you use in reading, writing, and language arts?

Reading:

Writing:

Language Arts:

None:

14. What is your PRIMARY method of instruction for teaching language arts? (Choose only one PRIMARY method.)

1) Individual Non-directed: Teacher operates as a counselor, helping students to understand themselves, clarify goals and direct their own activities.

2) Cooperative Learning: students learn and work together in heterogeneous groups (diverse skill levels) of students, to meet individual and group goals.

3) Individualized Mastery Learning: students work on individual goals to preset criterion levels in sequenced instructional modules. Individuals progress at their own rate.

4) Direct Instruction: students are taught in homogeneous (common skill levels) groups of students, following carefully sequenced instructional materials. All students meet preset criterion levels before moving to the next step. 
15. Age (Check only one)

\begin{tabular}{ll} 
1) & Under 30 \\
2) & $30-40$ \\
3) & $40-50$ \\
\hline 4) & Over 50
\end{tabular}

16. Gender (Check only one)
1) Female
2) Male

17. How long ago was your most recent course or inservice in reading, writing, or language arts? (Check only one)

1) Less than 1 year

2) 1 - 3 years

3) 3 - 5 years

4) 5 - 10 years

5) More than 10 years

18. Do you plan to take a course or inservice in reading, writing, or language arts within the next year? (Check only one)

1) Yes; specify course/inservice:

2) No

19. Please indicate the number of students receiving free or reduced lunch in your fifth grade class (\# of F/R Iunch)

Please List:

1) Endorsements:

2) Highest Degree:

3) Number of years teaching: 
APPENDIX C

STUDENT QUESTIONNAIRE 
** Office Use Only **

Student Number

RCS

\section{STUDENT QUESTIONNAIRE}

Sample: Do you like to ride a skateboard? (check only one)

(1) Often

(2) Sometimes

(3) Never

For each question, make a check mark on the line next to the answer you choose.

1. Do you like to read? (check only one)
(1) Often
(2) Sometimes
(3) Never

2. Do you like writing projects? (check only one)
(1) Often
(2) Sometimes
(3) Never

3. Do you like to ride a bike? (check only one)
(1) Often
(2) Sometimes
(3) Never

4. When you have free time in school, what is the first thing you would choose to do? (check only one)
(1) write a story
(2) do home work
(3) read a book
(4) use the learning center
(5) talk with friends

5. When you have free time in school, what is the second thing you choose to do? (check only one)
(1) write a story
(2) do home work
(3) read a book
(4) use the learning center
(5) talk with friends

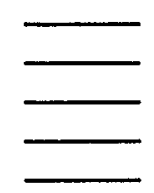


6. When you have free time at home, what is the first thing you would choose to do? (check only one)

(1) do your home work

(2) read a book

(3) ride a bike

(4) write a story

(5) play with friends

(6) watch television

(7) do your chores

7. When you have free time at home, what is the second thing you would choose to do? (check only one)

(1) do your home work

(2) read a book

(3) ride a bike

(4) write a story

(5) play with friends

(6) watch television

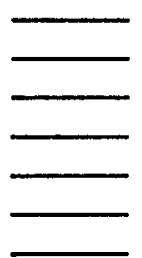

8. List what you have read in the last month. Include everything you can think of. If you need extra space, use the space on the back of this page.

9. What is you favorite television show?

10. How many books have you read in the last month? (check only one)
(1) 0
(2) $1-5$
(3) $5-10$
(4) Over 10

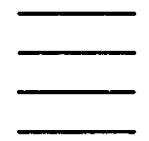

11. Are you a boy or a girl? (check only one)
(1) Boy
(2) Girl

12. How old are you? (age in years) 
13. How much time did you spend reading outside of school this week? (check only one)
(1) None
(2) 30 minutes
(3) More than 30 minutes

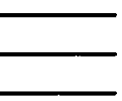

14. Why did you read last week? (check only one)

(1) Class assignment

(2) Wanted to

(3) Another reason

15. What was the title of the last book you read?

16. What is your favorite book? 
APPENDIX D

SCATTERGRAMS 


\section{SCATTERGRAMS}

\section{Do you like to read?}

Student Answer

Often
Sometimes
Never

$$
\begin{aligned}
& \begin{array}{rrr}
6 & 9 & 20 \\
1 & 9 & 9
\end{array} \\
& \begin{array}{lllllllllllllll}
1 & 2 & 3 & 4 & 5 & 6 & 7 & 8 & 9 & 10 & 11 & 12 & 13 & 14 & 15
\end{array}
\end{aligned}
$$

Teachers' Itoplemtation Scores

2. Do you like writing projects?

\begin{tabular}{|c|c|c|c|c|c|c|c|c|c|c|c|c|c|c|c|}
\hline \multirow[t]{2}{*}{$\begin{array}{r}\text { Often } \\
\text { Somet imes } \\
\text { Hever }\end{array}$} & $\begin{array}{l}3 \\
3 \\
1\end{array}$ & & $\begin{array}{l}2 \\
8\end{array}$ & $\begin{array}{r}9 \\
25 \\
4\end{array}$ & & & & & $\begin{array}{r}5 \\
17 \\
7\end{array}$ & $\begin{array}{l}6 \\
6\end{array}$ & $\begin{array}{l}3 \\
1\end{array}$ & $\begin{array}{r}13 \\
2\end{array}$ & 2 & 6 & 5 \\
\hline & 1 & 2 & 3 & 4 & 5 & 6 & 7 & 8 & 9 & 10 & 11 & 12 & 13 & 14 & 15 \\
\hline
\end{tabular}

student Answer

Teachers' Impleantation Scores

3. When you have free time at school, what is the first thing you would choose to do?

\begin{tabular}{|c|c|c|c|c|c|c|c|c|c|c|c|c|c|c|c|}
\hline $\begin{array}{r}\text { write a story } \\
\text { do homework } \\
\text { read a book } \\
\text { learning center } \\
\text { talk w/friends }\end{array}$ & $\begin{array}{l}1 \\
7 \\
7\end{array}$ & 2 & $\begin{array}{l}4 \\
2\end{array}$ & 4 & 5 & 6 & 7 & 8 & $\begin{array}{r}3 \\
5 \\
11\end{array}$ & $\begin{array}{r}3 \\
5 \\
8 \\
2 \\
22 \\
10\end{array}$ & $\begin{array}{r}5 \\
4 \\
9 \\
19 \\
11\end{array}$ & $\begin{array}{r}9 \\
20 \\
12 \\
3 \\
20 \\
12\end{array}$ & $\begin{array}{c}2 \\
3 \\
6 \\
3 \\
2 \\
13\end{array}$ & $\begin{array}{r}4 \\
11 \\
7 \\
23 \\
14\end{array}$ & $\begin{array}{r}1 \\
2 \\
7 \\
18 \\
15\end{array}$ \\
\hline
\end{tabular}

Student Answer

Teachers" Implementation Scores

4. When you have free time at home, what is the first thing you would choose to do?

Student Answer

\begin{tabular}{|c|c|c|c|c|c|c|c|c|c|c|c|c|c|}
\hline $\begin{array}{l}5 \\
3 \\
3\end{array}$ & & $\begin{array}{l}4 \\
2\end{array}$ & $\begin{array}{l}8 \\
2 \\
4\end{array}$ & & & & & $\begin{array}{l}6 \\
7 \\
3\end{array}$ & $\begin{array}{l}8 \\
1 \\
4\end{array}$ & $\begin{array}{l}2 \\
1 \\
2\end{array}$ & $\begin{array}{r}18 \\
7 \\
4\end{array}$ & $\begin{array}{l}6 \\
3 \\
5\end{array}$ & $\begin{array}{l}5 \\
4\end{array}$ \\
\hline $\begin{array}{l}9 \\
4\end{array}$ & & $\begin{array}{l}9 \\
3 \\
1\end{array}$ & $\begin{array}{l}5 \\
7 \\
2\end{array}$ & & & & & $\begin{array}{l}8 \\
5\end{array}$ & $\begin{array}{r}16 \\
5 \\
5\end{array}$ & $\begin{array}{r}16 \\
5 \\
2\end{array}$ & $\begin{array}{r}18 \\
4 \\
9\end{array}$ & $\begin{array}{r}12 \\
7 \\
4\end{array}$ & $\begin{array}{r}18 \\
5 \\
4\end{array}$ \\
\hline 1 & 2 & 3 & 4 & 5 & 6 & 7 & 8 & 9 & 10 & 11 & 12 & 13 & 16 \\
\hline
\end{tabular}

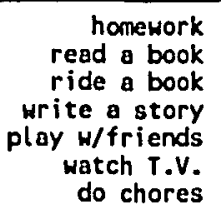

Teachers' Implementation Scores 
5. How many books have you read in the last month?

Student Answer

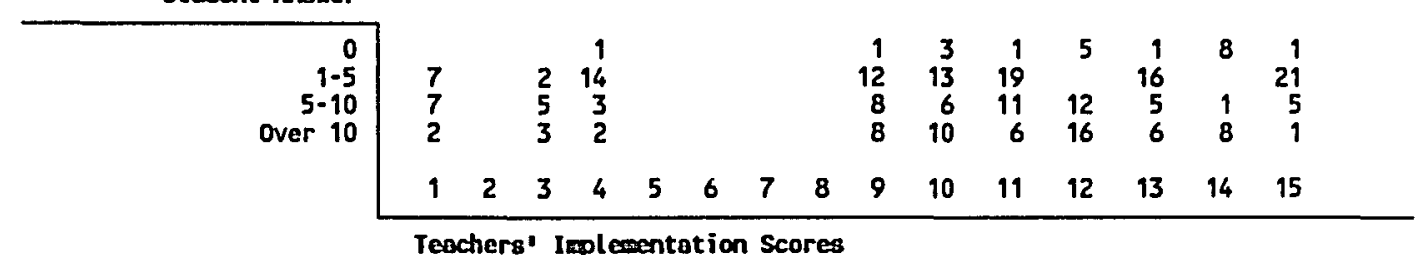

Teachers' Implementation Scores

6. How much time did you spend reading outside of school this week?

Student Answer

none

thirty minutes

$\begin{array}{rrr}7 & 2 & 3 \\ 9 & 2 & 2 \\ & 6 & 24\end{array}$

3
2
24
4

$\begin{array}{rrrrrrr}6 & 2 & 5 & 7 & 5 & 1 & 5 \\ 9 & 8 & 7 & 11 & 1 & 7 & 8 \\ 21 & 21 & & & & 25 & 22\end{array}$

12

910

$\begin{array}{lllll}11 & 12 & 13 & 14 & 15\end{array}$

Teachers' Implenentation Scores 